\title{
Closing the Gap
}

\section{Román Mayorga}

Washington, D.C.

January 1997- No SOC-104 
This document was prepared by Román Mayorga, Principal Specialist in Education, Science and Technology of the Social Programs Division, Department of Social Programs and Sustainable Development of the InterAmerican Development Bank, with contributions from the following Bank staff members: Carlos Abeledo, Mauricio Bertrand, Luis René Cáceres, Claudio de Moura Castro, Xavier Comas, Luis de Sebastián, Leo Harari, Bernardo Kliksberg, Juan José Llisterri, Patricia Meduña and Emil Weinberg. The author would like to express his gratitude to those persons and to Eduardo Feller, of the National Science Foundation of the United States, Lauritz Holm-Nielsen, of the World Bank, Orlando Mason, of the Organization of the American States and Sergio Trindade, of SE T International, for their comments and suggestions. The opinions stated in this paper are those of the author and do not necessarily reflect the policies of the InterAmerican Development Bank. 


\section{Summary}

This document deals with the support that the Inter-American Development Bank (IDB) can offer for creating, disseminating, and making practical use of knowledge in the countries of Latin America and the Caribbean (LAC). Unlike the approach taken by other international financial institutions in the 1960s, at the outset of that decade the IDB began financing the development of higher education and science and technology. Since then, it has approved many loans and technical cooperation operations in those fields and for agricultural research and extension activities, middle-level technical education, and job training. The IDB's contribution has been the main, although by no means the only source of external support for science and technology development in LAC for more than three decades. Although the region's capacity in this field is relatively weak in comparison with other developed and newlyindustrialized countries, it would have been much weaker without the Bank's support.

Knowledge is increasingly recognized throughout the world as the most important resource of nations and a determining factor in their competitiveness on international markets. This study seeks to explain how the IDB has envisioned and performed its work in science and technology (S\&T) and to offer a conceptual basis for a new strategy, needed to assist the region in tackling the challenges of the twentyfirst century with respect to knowledge. The document presents a review of institutional memory in chapter I and an analysis of current issues in chapter II, as background for future efforts. Chapters III and IV make suggestions for specific actions for different kinds of countries. Chapter V discusses S\&T financing problems which are of special interest for the Bank, explains possible objectives of its strategy and includes an example of what a program financed by it might be like. The table on the following page summarizes the problems that should be addressed, the suggested objectives for the Bank's strategy and the typical tools that would be used to implement it. 
SUMMARY OF BASIS FOR A SCIENCE AND TECHNOLOGY STRATEGY

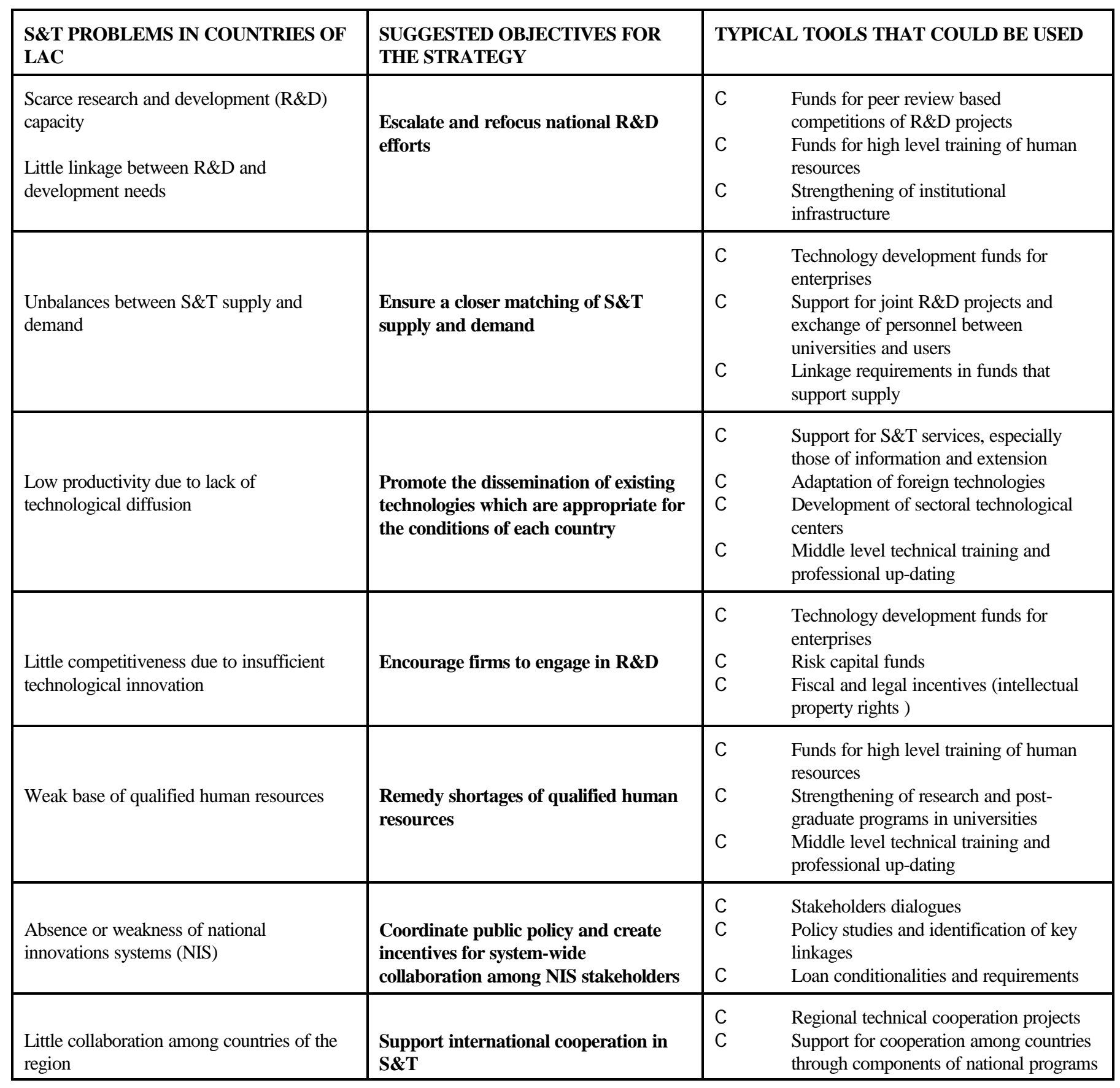




\section{Contents}

I. IDB experience in science and technology $\ldots \ldots \ldots \ldots \ldots \ldots \ldots \ldots \ldots \ldots \ldots \ldots$

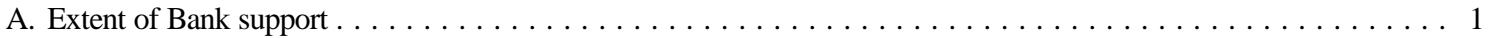

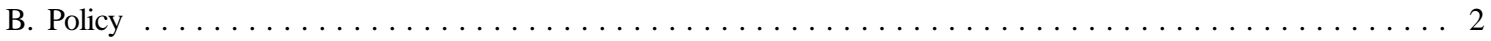

C. Stage one (1961-1987): Building up capacity in universities

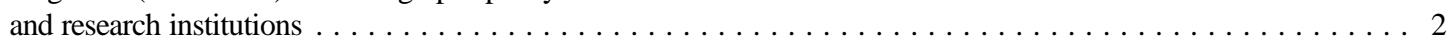

D. Stage two (1988-1996): Consolidation of S\&T institutions

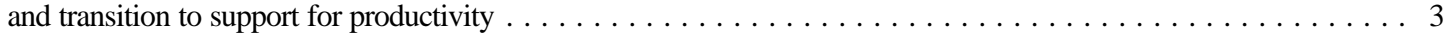

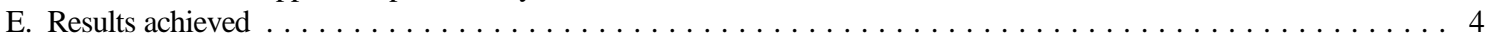

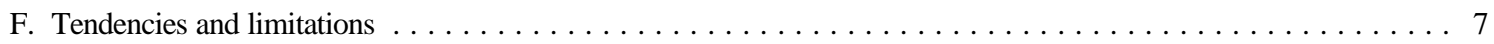

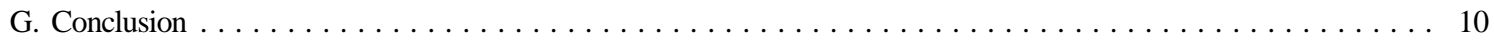

II. Science and technology interfaces $\ldots \ldots \ldots \ldots \ldots \ldots \ldots \ldots \ldots \ldots \ldots \ldots \ldots \ldots \ldots \ldots \ldots \ldots \ldots$

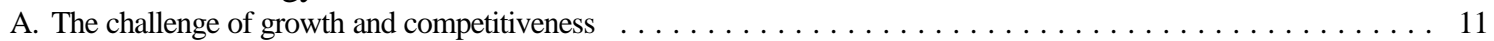

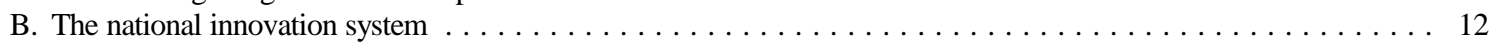

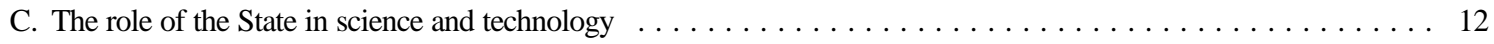

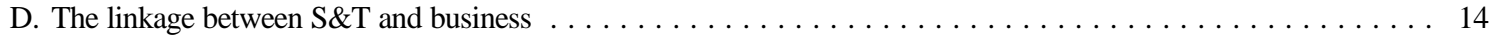

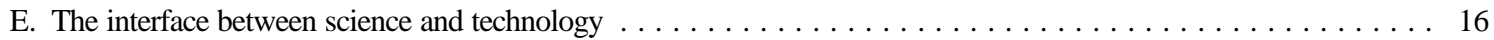

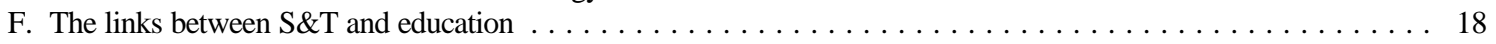

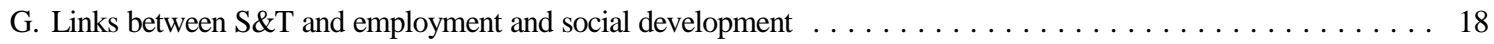

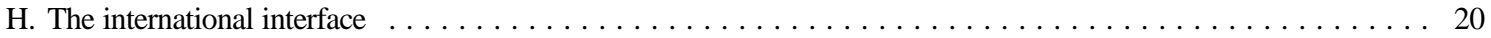

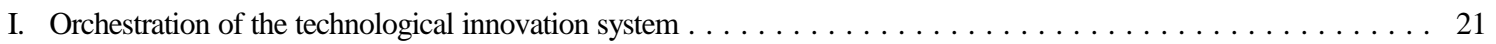

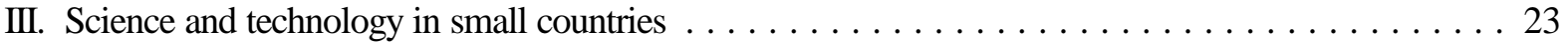

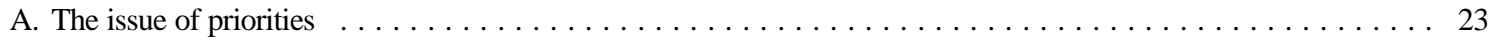

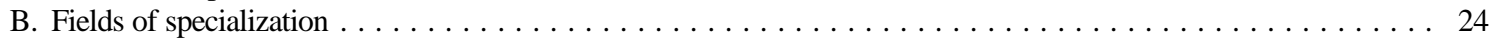

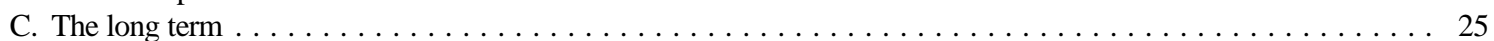

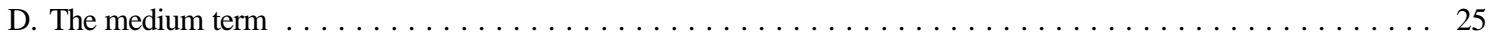

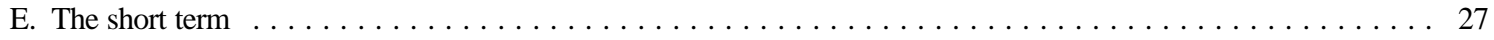

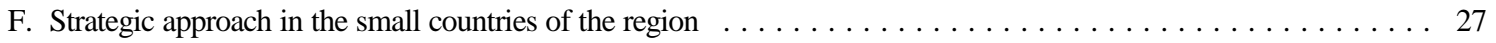

IV. Science and technology in large and medium-sized countries $\ldots \ldots \ldots \ldots \ldots \ldots \ldots$

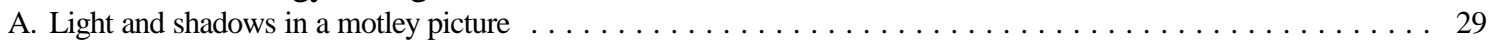

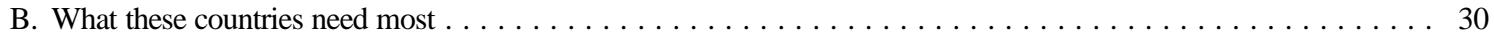

C. Promotion of technological innovation in the context of globalization $\ldots \ldots \ldots \ldots \ldots \ldots \ldots \ldots \ldots \ldots \ldots \ldots$

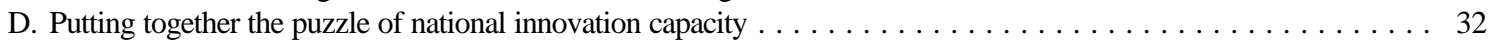

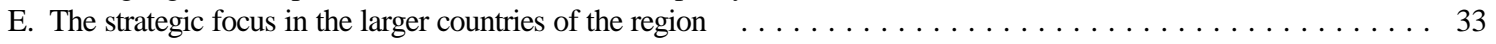

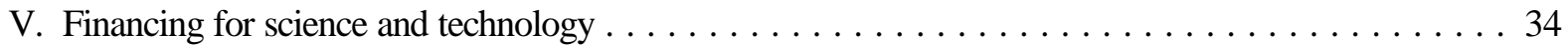

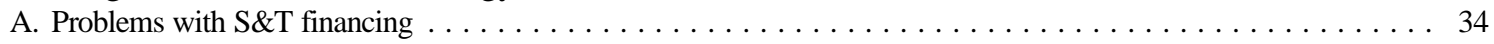

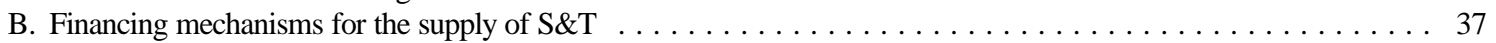

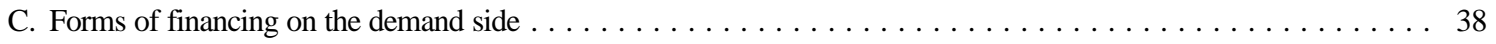

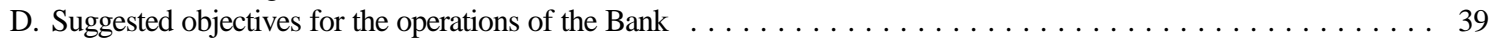

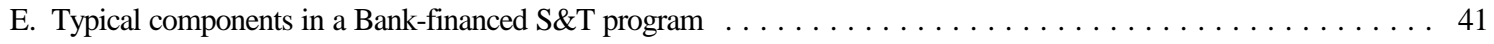

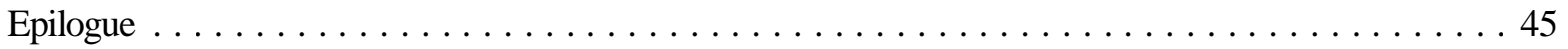

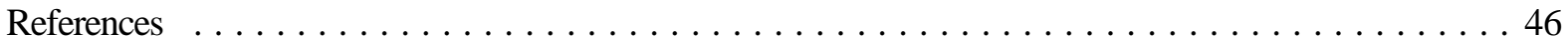




\section{-I- \\ IDB experience in science and technology}

The IDB contributes to the development of science and technology in the borrow

in different $w$

in the projects it fin

nomi

ture needed for S\&T development. Bank nonreimbursable technical cooperation operations contribute to interna

skills. The goods and services procured with loans frequently incorporate new knowledge which becomes part of the productive store of the countries through project execution.
A.

\section{Extent of Bank support}

\section{In ad}

$\boldsymbol{S} \& \boldsymbol{T}$ that the IDB has provided through the cumulative impact of its operations in all sectors, thus far it has contributed almost US\$3.8 billion in direct aid for that purpose. A summary of loans and nonreimbursable technical cooperation operations most directly related to S\&T development is given in Table No 1, classified by the IDB fields and operating policies. 


\section{Table No 1}

\section{IDB operations directly supporting S\&T development in LAC}

(From 1/I/61 to 31/XII/96; US\$ millions in current prices of the years in which operations were approved)

\begin{tabular}{||l|c|c|c|c|c|c||}
\hline Field by IDB classification & $\begin{array}{c}\text { IDB } \\
\text { operating } \\
\text { policy }\end{array}$ & $\begin{array}{c}\text { Number } \\
\text { of } \\
\text { loans }\end{array}$ & $\begin{array}{c}\text { Loan } \\
\text { amount }\end{array}$ & $\begin{array}{c}\text { Technical } \\
\text { cooperation } \\
\text { amount }\end{array}$ & $\begin{array}{c}\text { Total IDB } \\
\text { contribution }\end{array}$ & $\begin{array}{c}\text { Total cost of } \\
\text { projects } \\
\text { (estimated) }\end{array}$ \\
\hline Science and technology & OP-744 & 31 & $1,323.2$ & 41.7 & $1,364.9$ & $2,616.5$ \\
\hline Higher education & OP-743 & 78 & 687.1 & 32.0 & 719.1 & $1,336.3$ \\
\hline $\begin{array}{l}\text { Middle-level technical education } \\
\text { and job training }\end{array}$ & OP-743 & 34 & 621.9 & 42.1 & 664.0 & $1,046.0$ \\
\hline $\begin{array}{l}\text { Agricultural research and } \\
\text { extension }\end{array}$ & OP-721 & 29 & 863.0 & 181.4 & $1,044.4$ & $1,855.6$ \\
\hline Total & & 172 & $3,495.2$ & 297.2 & $3,792.4$ & $6,854.4$ \\
\hline
\end{tabular}

B.

Policy

The earliest IDB loans for science and technology (1961-1967) were made without an explicit policy in this field. $\mathrm{T}$

and development (R\&D) physical infrastructure of public institutions such as the Argentine National Atomic Energy Commission (loan 91/SF-AR) and the Mexican Technology Research Institute (33/TF-ME).

In 1968, the Bank's Board of Executive Directors approved an explicit science and technology policy (OP-744) which still remains in effect. All subsequent science and technology operations have been carried out under that policy, which is distinct from the Bank's education policy (OP-743) and its agricultural research and extension policy (OP-721, number 2). This summary refers in particular to those operations, although the IDB's contribution in this field goes beyond a single policy or classification, as mentioned earlier.

The Bank's operating policy (OP-744) establishes that its objective is to participate in "promoting progress in science and technology in Latin America" both indirectly and directly through its lending and technical assistance for research and post-graduate studies at universities. It may also "support institutions and activities other than those which have traditionally received support in the field of education." The policy establishes and explains in detail the fields of activity that are eligible for Bank financing, such as scientific and technological services, national science and technology organizations, creation of demand, support to prevent the emigration of scientists and technical personnel, support for basic and applied research, training for researchers, technological research institutes, and institutes of standards. However, OP-744 does not establish priorities or rankings among the different areas that are eligible, nor does it set out time sequences or causal relations between given objectives and means. The policy appears to have been deliberately designed to be very broad, to permit IDB-supported projects to be flexibly adjusted to the special nature of each time period and country.

In order for the Bank to approve a loan or a 
technical-cooperation operation, the government of the borrowing country must assign high priority to the project during the programming exercise with the Bank, and it must be demonstrated that the program in question would make a significant contribution to the country's economic and social development. The potential contributions of all the project components and the country's current capacity to ensure that those contributions will be made with the support of project funding must be spelled out. This core aspect of a project is subject to an interdisciplinary review by the Bank, as are related aspects such as proper correlation between objectives and means, justification of the scale of the project components and the linkage between them. It is also necessary to demonstrate the feasibility of an efficient project execution, which is subject to a detailed analysis by the Bank.

\section{C.}

\section{Stage one (1961-1987): Building up capacity in universities and research institutions}

Despite the flexibility of the Bank's policy, its science and technology lending operations in the 1960s, 1970s, and much of the 1980s, focused almost exclusively on activities and investments for a single basic purpose: the creation of $R \& D$ capacity in universities and public research centers. The objective was largely pursued through two types of instruments: (a) post-graduate scholarships abroad for the training and specialization of researchers from such institutions; and (b) investments for the construction and equipping of $R \& D$ infrastructure, such as laboratories, libraries, and computer centers. Loan proceeds were generally channeled through national science and technology councils or institutions such as CNPq and FINEP in Brazil, CONACYT in Mexico, CONICET in Argentina, and COLCIENCIAS in Colombia.

Although no general strategy document other than OP-744 was produced between 1961 and 1987, the Bank's project reports regularly contained analyses which, in sum, identified the main problem as being the region's weakness in $R \& D$, mainly conceived as academic research, and affirmed that meaningful science and technology activities could not be carried out without sufficient well-trained scientists and wellequipped laboratories. The main strategy was, therefore, implicit but clear: where capacity was lacking or too limited, the first step was to create it or strengthen it, wi $\mathrm{f}$

Sinc

economic and social development of its member countries, it was crucial to ensure the "relevance" of the proposed investments. This was generally done through an analysis of the potential contribution of operations to specific objectives of economic growth or the satisfaction of social needs. Also, and with increasing frequency since 1988, the Bank used methods of economic analysis under uncertainty to calculate the probable returns from $R \& D$ projects. This practice was based on the argument that the rigor of this analytical exercise, rather than the resulting numbers, would help to increase the relevance of investments and to produce cultural changes in the scientific community, increasing awareness of the costs and potential benefits of R\&D. In fact, the programs financed by the Bank have contributed, as will be discussed later, to foster the selection of research topics which are related to economic and social development.

Aside from relevance, stress was also laid on quality and economies of scale in $R \& D$. Not only were competent researchers and suitable equipment necessary to effectively produce $R \& D$ results, but issues needed to be addressed arising from crossfertilization between disciplines, the zones in which they overlap, and the establishment of systems of knowledge in which different types of technologies and sciences interact and converge. This meant that effective specialization in a country in any field was not opposed to, but required, some degree of general scientific capacity to work competently in interdependent areas. There was also a need for certain levels 
of critical mass in order for progress to be made in this field, which had long ceased to be the kingdom of the scientific genius working alone in a laboratory. In general, in this first stage of operations, the Bank placed more stress on building up overall capacity than on developing areas of specialization.

D.

\section{Stage two (1988-1996): Consolidation of S\&T institutions and transition to support for pro- ductivity}

Toward the close of the 1980s, a second strategic objective in Bank S\&T operations became clear: direct stimulation of demand by private enterprise and the consequent establishment of linkage between producers and users of knowledge and techniques. This objective has appeared pro in all $\mathrm{S} \& \mathrm{~T}$ proje

book by the President of the IDB (E.V. Iglesias, 1992), and in some general publications on S\&T by the former Project Analysis Department (PRA, 1989), which was responsible for the technical preparation of Bank operations in this area.

This new objective responded to the shift away from the growth model based on import substitution that almost all the

ing or considering, and the de

tivity and international competitiveness of economic activities. Many countries sought the Bank's aid in increasing the technological capacity of their companies to enable them to compete better on ever larger and more demanding markets. These concerns became more intense precisely at a time when, thanks to the investments made in past decades, the institutions in some of the countries had the capacity to begin to respond adequately to the challenge of competitiveness. It was necessary to make better use of the capacity that had already been created in order to help businesses survive and progress in more competitive circumstances. This began to expose the limitations of financing for S\&T on the supply side and led to a search for mechanisms to advance technological development and innovation inside industry

knowledge to

ble.

The Bank used different instruments to promote these objectives in its operations, generally drawn from the fledgling experiences of the countries in the region and often inspired by the practices of developed countries outside the region. Technology development funds have been a major instrument that directly provides financing and technical assistance for businesses that wish to carry out or contract their own R\&D or to introduce technological innovations. Some of these funds were established with IDB financing and others were strengthened under IDB loans.

prominently

Other tools used to help consolidate S\&T institutions, boost the private sector productivity, and develop linkage between the latter and national science and technology centers have been: (a) the eligibility requirements and evaluation methodologies for R\&D projects in universities and public institutions which, since 1988, have required that ties be sought with potential users to gain access to loans; (b) taxonomic changes in the classification of $\mathrm{R} \& \mathrm{D}$ which more clearly identify research whose results are transferable to socioeconomic activities within given time frames, and control variables that increase the amounts earmarked for this type of R\&D; (c) projects for technology linkage between universities and businesses, such as the SECYTs in Argentina (loan 802/OC-AR) and FONDEF in Chile (672/OC-CH); and (d) science and technology services agencies (sometimes called "technology support infrastructure"), such as the Standards and Quality Control Institute, the Electronic Microscopy Unit, postharvest, structures and materials testing laboratories, and the technology extension and information offices of Costa Rica (544/OC-CR). The Bank also helped to launch and implement the Bolívar Program, one of whose objectives is to foster ties between businesses and universities located in different countries of the 
region.

\section{E.}

\section{Results achieved}

The Bank has not yet performed a systematic evaluation of the impact of the $S \& T$ programs it has financed, although the Evaluation Office (EVO) has initiated work on a "policy/program evaluation" and the Social Programs and Sustainable Development Department (SDS) is preparing a study of sucessful cases of technological innovation in the region. The following information is, therefore, partial. It is based on a rev

proposals, progress reports by borrowers, and missions conducted by Bank staff and consultants (see references under Banco Interamericano de Desarrollo).

The availab train some 20,000 Latin American researchers. IDB assistance has also contributed to the strengthening of at least 100 universities and science and technology institutions, including those that probably are now the most advanced in the region. The list includes the University of Sao Paulo, the Autonomous University of Mexico, the Simon Bolivar University in Venezuela, the University of Chile, the University of Costa Rica, the University of the Republic of Uruguay, and the University of the West Indies. National science and tech

bia, Costa Rica, Ecuador, Mexico, Uruguay, and Venezuela benefited from IDB support, as did technology development funds in Argentina (FONTAR), Brazil (FINEP/ADTEN), Chile (FONTEC), Colombia (COLCIENCIAS), Costa Rica (FODETEC), Mexico (FIDETEC), and Uruguay (FINTEC). Since $S \& T$ capacity fundamentally depends on competent personnel, infrastructure and institutional development, it is clear that the IDB made an important contribution to it in some countries of the region.

The few formal ex post evaluations conducted by the countries confirm good results. One evaluation report (Teubal, M., 1994) of S\&T activities financed in Chile concluded that "the programs are well designed and appear to operate harmoniously and with relative effectiveness." The report found that the Technology Development Fund (FONTEC) provided effective support for a significant "learning to innovate" process in the private sector, while the $S \& T$ Development Fund (FONDEF) helped to strengthen R\&D capabilities in universities and institutes of technology that are relevant for the country's development. Another independent evaluation by INVERTEC IGT (1995) concluded that: "in the vast majority of cases involving small businesses, which constitute two thirds of the universe, the projects would not have been carried out without FONTEC" and "FONTEC financing is generating from 5 to 6 pesos in value added tax for each peso allocated, without considering other benefits in the form of jobs, indirect impact and, of course, the strengthening of innovative enterprises". Two evaluations conducted in Colomb

$\mathrm{Nac}$

con

capacity in universities and the budding process of learnin

sectors. Some examples of successful technological innovation follow, among hundreds of cases to which the borrowing institutions of the Bank have contributed resources.

In Argentina, results worthy of mention include: a pioneering biotherapeutic milk product, already available throughout the country, that restores the intestinal flora in children suffering from diarrhea; a rotavirus vaccine for calves, now in commercial production, which has driven the incidence of the corresponding disease from more than 40 percent to below 9 percent and reduced the death rate in afflicted calves from 5.4 percent to 0.2 percent; an ester sweetener derived by cloning a natural herb, with a pilot plant about to begin operations; a reagent to diagnose Chagas disease for which mass marketing plans are being negotiated with international pharmaceutical firms; and a new catalyst for oxidizing 
carbon monoxide now on the market and in use in a number of catalytic cracking plants (Fundación Centro de Biosíntesis, 1996).

In Brazil, genetically engineered varieties of soybeans and sugar, now widely available, have already had considerable economic and social impact. Biotechnology has also led to cancer drugs, such as platinil and neoplatine, that match the efficacy of alternative drugs available on the international market but sell for 70 percent less. Innovations in deep-water oil prospecting and production include wet (subsea) Christmas trees and manifolds and a robot that operates to 1,000 meters, greatly easing maintenance. Brazilian microwave antennas already serve half the domestic market for high-speed data transmission; these antennas are now being exported, as well as telephone switchboards, computer software and other high value-added products (Magalhães Castro, M. H., 1996).

In Chile, new techniques of detecting and controlling tomato canker, one of the most serious plant health problems facing the production of this vegetable, has permitted large reductions in pesticide applications. Crop yields have risen. Other innovations include: a clean process for producing copper oxide, a pigment used in marine paints, not previously manufactured in Chile; an automated process monitoring system for fishmeal presses, which has improved the quality of this product and helped exporters improve their competitiveness; a dry spray treatment used in fabricating processed wood products; improvements in computer software used to manage open-pit mine operations (CORFO, 1995).

In Colombia the list includes: a malaria vaccine that seems to be more effective than any other now available (Spurgeon, D. 1995); a process for producing fumaric acid, widely used in food processing and also in resins, starting with waste water from other chemical processes; a new method for enhancing natural flavors using soybean flour, wheat gluten and corn germ vegetable proteins, now in pilot production; new valves for keeping a constant downstream pressure and a microprocessor-controlled mobile $\mathrm{x}$ ray unit, low in cost and versatile (COLCIENCIAS, 1994).

In Costa Rica, several Costa Rican firms have introduced computer software for applications ranging from manufacturing process control to education. In another case, satellite signals have been used to help locate fish off the Central American coast. A new microelectronic device has been developed to modernize existing telephone exchanges at low cost. Special safety boxes for financial institutions have been designed and exported. A start-up firm has developed a chemical product that is used by a large multinational corporation to polish quartz crystals. Waste-water treatment proce in cheese factories, as have methods for reducing post-harvest losses in agriculture (Sibaja, E., 1996).

In Uruguay, a "selective inverted sump" patented by a Uruguayan academic provides the basis for an effective method, already used by a large exporter of citric fruits, of protecting agricultural crops against radiative freezing; a local firm developed a new process for producing lanolin from wool fat, which eliminates pesticide residues an and safety standards of importing countries; a new clean method for using plastic waste in energy production is being tested in a pilot plant; electrical transformers that are more resistant to sudden power surges have been developed and exported, and an electronic hearing aid, originally developed in the United States, is being adapted for severely deaf Spanish speakers, for whom the U.S. version, optimized for English, does not work well (Roche Rivera, $\mathrm{H}$

Peer reviews of $R \& D$ projects competing for funding have been an effective practice for establishing strict quality standards for R\&D which the Bank has helped to introduce and spread in the region. This practice, which arose from the editorial boards of scientific journals and was disseminated by the United 
States National Science Foundation, has been regularly included in designing the Bank's S\&T operations. At least 12 countries have held competitions of this type with Bank support, and there is evidence that they have helped to raise the quality of scientific production in the region. For example, in the four years since competitions based on peer review were established in Uruguay, the annual number of articles by Uruguayan authors mentioned in the Science Citation Index has doubled, and the number of international citations of each of these articles has increased by over 30\% (CONICYT, Uruguay 1995).

The Bank has played a modest role in developing horizontal cooperation among countries in $S \& T$. Some of its most important operations of this type have been support for the Bolívar Program, regional agricultural research centers, and the countries of the English-speaking Caribbean through their regional university. The Bank has also participated in the hemispheric efforts of United Nations agencies, particularly UNESCO, the Or

States, the Secretariat of the Andrés Bello Agreement, the

However, its spending on intra-regional science and technology

actual needs.

From an operational standpoint, loan disbursements and project execution have been reasonably efficient in most cases, but have not been exempt from different problems th

is possible here. The Bank's rating system distinguishes four categories of project performance. In descending order, these are termed normal, slow, difficult, and problematic (1995 Annual Report on Portfol

10 current S\&T programs were rated normal. The other, at the time nearly completed, was classed as slow because of problems in counterpart financing. S\&T performance overall is considerably better than the average for all Bank projects. Of 259 active projects in all Bank areas, 67 percent were rated normal, 23 percent slow, 5 percent difficult and 5 percent problematic. S\&T compares even more favorably with projects classed as social programs; a sampling of 33 such projects were rated 49 percent normal, with 27 percent slow and the remaining 24 percent split equally between difficult and problematic.

\section{F. Tendencies and limitations}

\section{A fundamental change occur} $S \& T$ projects financed by the IDB toward the end of the 1980s, with an increase in applied research and experimental development. When comparing the period 1961-1987 to 1988-1996, a large reduction can be seen in the percentage of investments in the infrastructure of universities and public research institutions and both a relative and absolute increase in spending on $\mathrm{R} \& \mathrm{D}$, particularly those that were conducted or contracted out by private companies. After 1987, only threeguniversities received IDB loans for major laboratory infrastructure, in Uruguay I (646/OC-UR), the English-speaking Caribbean ı(The University of the West Indies, 679/81-OC-RG) and Mexico (804/OC-ME). All the programs in this field included substantial resources for R\&D whose results could be immediately transferred to the production apparatus. The percentage of funding for corporate $\mathrm{R} \& \mathrm{D}$ rose to $70 \%$ in Brazil (620/OC-BR), $49 \%$ in Argentina (802/OC-AR) and $31 \%$ in Colombia (875/OC-CO). In the preceding 25 years these figures had been zero or negligible.

The changes in proportion mentioned above are even more significant considering that there was also a large increase in the volume of financing for S\&T programs. Over two thirds of the cumulative total since 1961 was approved after 1987. The shift in the focus of programs has therefore acted as a major stimulus for introducing the study of areas of practical interest that produce results for society within a reasonable time into university research and has been one of the few efforts in the region to 
directly promote R\&D in businesses. Some authors have criticized this change, because they believe it goes too far in the direction of commercializing knowledge to the detriment of long-term actions, basic skills, and the independence of

I., 1995). However, if the chasm between academic research in the region and the socioeconomic needs of the countries is considered, it can be concluded that the shift in emphasis of the programs financed by the IDB was probably in the right direction.

IDB loans for science and technology development have gradually become more complex. After the loans in stage one, which were limited to providing financial resources for infra for the staff of one or two entiti institutions), operations began to and more institutions. The technology development funds for businesses, metrology, standardization and qual and industries, and other and demand, are all part of this trend. However the Bank's policy (OP-744) does not refer explicitly to the systemic nature of the science and technology capacity of the countries, nor does it call for an analysis of the interconnections between the components of projects to achieve synergy through mutual reinforcement.

One of the consequences of the economic crisis of the 1980s was the gradual abandonment of largescale, high-cost science projects (nuclear energy, optic fibers, etc.) by the countries that had been conducting them. Pressured by cutbacks in public funds, some research groups increased their contacts with businesses and agreed to cooperate with them in less ambitious efforts. Although truncated projects, sunk costs, and frustrated expectations are a high price to pay, a more pragmatic attitude and a willingness to cooperate with other sectors appears to have arisen. It is possible that Bank financing has facilitated realistic adjustments in such cases.
No evidence is available on the impact of Bankfinanced $S \& T$ programs on income distribution and wealth, which has never been evaluated in any past or present program. Project reports (see for example PR-1602, PR-1806, PR-1827, PR-1969, tra dRRi-2062) suggest that the state of the art does not allow for reliable quantifications of the distributional impact of programs of this kind, giving reasons such as the impossibility of predicting the nature of the results of research or when they will be available and the need for additional investments to obtain their full benefits. Justification of these programs was never approached in terms of equity but rather in terms of growth and competitiveness, since there are other instruments that are better suited to addressing social injustice in the region. However, it is possible that these programs have had some positive impact on access to knowledge (Sutz, J., 1993), which is an important source of power, and on other aspects of social development, such as health care, nutrition, women's participation, and environmental protection.

Enrolment by women in institutions of higher education in the region has grown much faster than the already high rate of increase in total enrolment (see Bank project reports), rising from just below $25 \%$ in the 1960 s to almost $50 \%$ in the 1990 s, and even more in some countries. In view of the shortage of S\&T funds from other sources, the programs financed by the Bank have made a major contribution to education and job opportunities in this field for Latin American women. However, far fewer women than men engage in S\&T studies, particularly in engineering, and in high-level intellectual activities such as $R \& D$ and university teaching. The percentage of women out of total teaching and research staff of universities i

American countries. This could possibly be due to social stereotypes that assign different roles to men and women, based on supposed differences in talent for different activities. The World Conferences on Women, from Mexico to Beijing, have denounced these stereotypes and insisted on promoting equal participation by men and women in science and 
technology.

Technology's relationship with the environment has been ambivalent. On the one hand, the improper use of agricultural chemicals, acid rain, the dangers posed by nuclear plants, the thinning of the ozone layer, and other adverse environmental impacts are the consequences of how technology has been developed and used thus far. However, solutions to these and other inter-related problems, such as desertification, the extinction of species, air and water pollution, the degradation of watersheds, and the destruction of coastal resources, require knowledge and technology. Bank financing has stressed the development and dissemination of clean technologies that help to protect the environment or at least do not worsen deterioration, and the conservation and scientific management of natural resource

some positive experience

for example,

its forest science, oceanography an

capacity are producin

ing its considerable biodiversity and increasing income in foreign exchange from ecotourism.

Lack of continuity in budget allocations after the IDB-financ

problems in the region, in S\&T as well as in other areas. There are some exceptions, however. CONICYT in Chile and its mechanisms for channeling funding into research have been stable for many years, despite the changes in the country's politics. The last five Costa Rican and Colombian governments, despite changes in the parties in power, have maintaine

these and other cases, the Bank has generally been a reliable partner in the science and technology development of the countries, buttressing key institutions, cooperating in analyses, providing for the continui adverse cyclical fluctuations.

One major shortcoming in the Bank's science and technology activities was pointed out by the Executive
Director for Belize, Central America and Haiti in a memorandum dated June 16, 1995 (Hernández Alcerro, J.R.) to the Chairman of the Policy Committee of the Bank's Board of Executive Directors. This shortcoming is excessive concentration of IDB financing $i$

Group A and B countries. Close to $84 \%$ of lending operations classified as "science and technology" approved over the period 1961 to 1995 and about $94 \%$ of the respective financial resources went to Group A and B countries. This concentration is considerably higher than in other sectors, since just $45 \%$

and $63 \%$ of total financing went to Group A and B countries (IDB Annual Report, 1995). The situation is not the result of deliberate planning, but of the limitations typical of Group C and D countries and the absence of an explicit strategy that takes account of their needs and situations in this field.

There is a science and technology gap in the $\mathrm{f}$ region, as indicated by different yardsticks used to measure inputs and outputs of S\&T activities (CYTED/RICYT/OEA/MERCOCYT, 1996; UNESCO annual statistics; IRELA, 1993; Arregui, P., 1988; IDB, 1988; Cook, C. and Sagasti, F., 1987; Teitel S., 1985; Sercovich, F.C. and Teitel, S., 1984). One group of countries is relatively advanced: Argentina, Brazil, Chile, Mexico, and Venezuela. A second group now has significant national capacity and a specific institutional apparatus to promote S\&T: Colombia, Costa Rica, Uruguay, and the English-speaking Caribbean. The indicators for the other countries in the region generally point to a weak situation and, in some cases, to a complete absence of policies and institutions for national S\&T development. The varying degrees of capacity of individual countries to prepare adequate S\&T programs is one of the explanations for the IDB's financial concentration.

Despite the efforts made, there is a very wide gap in this field between Latin American countries and developed countries, including newly-industrialized 
nations. Taking technology generation as an indicator, the number of patents granted annually in the three leading countries (Mexico, Brazil, and Argentina) ranged from 3,160 to 663 in 1992 . The three next countries (Venezuela, Chile, and Colombia) issued between 481 and 248 patents. By contrast, Holland, Switzerland, and Taiwan each granted about 20,000 patents in the same year (International Institute for Management Development, 1994).

\section{All other indicators for inputs and outputs also} reveal very large differences between the countries that are most advanced in science and technology and the countries of Latin America and the Caribbean. Of the 43 countries whose competitiveness is evaluated in the World Competitiveness Report, 1994, including six from the region (Argentina, Brazil, Chile, Colombia, Mexico, and Venezuela), Latin America had the worst scores for science and technology. The country with the best indexes in Latin America ranked 20th in number of patents, 23rd in $\mathrm{R} \& \mathrm{D}$ personnel per 1,000 people in the work force, 26th in productivity per person employed, and 28th in spending on R\&D as a share of Gross National Product (GNP). The six most advanced Latin American countries generally ranked in the lowest third in competitiveness-related S\&T out of the 43 countries evaluated (MERCOCYT Program, 1995, based on data from the World Competitiveness Report, 1994).

The indicator generally used to measure scientific production

3,300 most respected journals in the world included in the database of the Science Citation Index of Philadelphia (which may be considerably biased against developing countries). It is significant to compare the most $r$

(1994) with those for some relatively small countries. Scientists from Switzerland, Israel, or Belgium publish more than all the scientists in Brazil and Mexico combined. Dutch or Swedish scientists publish more articles than all the scientists in Latin America and the Caribbean (Gibbs, W.W., 1995).
There is a fairly close correlation throughout the world between scientific production and per capita GNP. The mere existence of this correlation is not evidence of a causal relationship; and it is not clear at first glance whether scientific capacity generates or results from economic growth, or whether the two are the consequence of some other factor or combination of factors. However, the high dependency of modern production processes as well as society in general on scientific knowledge suggests that capacity in $S \& T$ is a necessary substructure and a contributing factor to development which, in turn, grows and is strengthened by development in a process of successive feedback.

Past experience in Europe and the United States certainly bears out the above hypothesis (see among others Rosenberg, N. and Birdzell, L.E., 1986; $\mathrm{K}$

and Rosenberg, N., 1993; Rosenberg, N., 1994). The same holds true in other countries which, in comparison with the United States and Europe, have placed greater stress on technological development than on science, although they too have invested much more in the latter than Latin America. Thirty years ago scientific production in the countries of East Asia (except for Japan) was lower than that of a number of Latin American countries. Currently, Taiwan's production is higher than Brazil's, South Korea produces more than Argentina and Mexico, and Hong Kong and even Singapore (with populations of less than 6 million and 3 million respectively) outstrip Chile, Venezuela, Colombia and all the other countries in the region except for the three largest producers. Comparisons between Japan and Latin America are much more unfavorable. Japan's total scientific output is already higher than that of Great Britain, Germany, and France, and is only surpassed by the United States (Gibbs, W.W., 1995). 
G.

\section{Conclusion}

The data obtained thus far, as summarized in the preceding pages, establish that the IDB has made a significant contribution over its 36 years of operations to the development of science and technology in Latin America and the Caribbean. However, efforts by the countries in $t$ and should be substantially increased in the future. There appear to be several significant shortcomings in policy OP-744 given the new

Althoug $\mathrm{h}$ of the countries, it does not specifically target them. Furthermore, the policy: (a) does not mention the different circumstances in the region or the different approaches that are therefore required in different cases;

edge than on its dis not make reference to the systemic nature of national $\boldsymbol{S} \& \boldsymbol{T}$ capacity or the importance of closer interrelationships between the different elements that constitute such capacity. Therefore, the very least that is required is a strategy to supplement policy OP-774 and to provide more specific guidelines for the course of future Bank operations. 


\section{-II- \\ Science and technology interfaces}

Today the organized body of knowledge that makes it possible to understand the causes of verifiable phenomena (science) and the application of knowledge to the production of goods and services (technology) permeate all sectors and activities of society. There are many areas in which the spheres of science and technology and the socioeconomic development of any country overlap. This chapter examines the interfaces ("the place at which a system meets or acts upon another" according to the Diccionario de la Real Academia Española, 1995) that are most relevant for a science and technology policy for Latin America and the Caribbean.

\section{A.}

\section{The challenge of growth and competitiveness}

Halfway through the final decade of the 20th century, economic globalization and the world technology revolution, especially in the fields of telecommunications and information technologies, mark our time and define the context in which the countries of the region will have to perform in the foreseeable future. Their production systems will be increasingly integrated into broad economic zones in which businesses sell their products on different markets and are supplied with components and factors of production, also coming from many different places. On those markets, technologically incompetent companies will be unable to compete commercially with high valueadded goods and services. Moreover, since technologies develop and change very quickly today, command over technological innovations will be an essential ingredient in the economic success of countries in the global market. Technology transformation in the twenty-first century will have a profound effect on economic growth, social services, the activities of governmen tion, and the general level at which the basic needs of the citizens of all nations are met.

Studies condu

of technological change on economic growth are worthy of mention, beginning with the works by Abramovitz, M. (1956) and Solow, R. (1957) who attributed most of the growth observed in that country in the first half of the twentieth century to a "residual" that was not explained by growth in the produ factors, which they identified as technical progress. Since then, many empirical studies have been conducted that directly link technological development to increases in production and productivity and measure returns from $R \& D$ in different periods, businesses, branches of industry, sectors, and countries. Denison, Evenson, Griliches, Kendrick, Link, Minasian, Nadiri, Peterson, Ruttan, Scherer, and Terleckyj, among other researchers, have contributed to this effor students at the University of Pennsylvania. Accorc ing to Mansfield, private returns from $R \& D$ in the cases studied are frequently on the order of $25 \%$ and social returns (which include benefits that cannot be appropriated by those who perform R\&D) often exceed $50 \%$. In a review of 30 years of literature, he concludes that levels of R\&D are closely linked to growth in productivity, that the rate of return on investments in R\&D is high, and that "it is remarkable that so many independent studies, based on so $\mathrm{m}$

conclusions" (Mansfield, E., 1986).

The above suggests that the great challenge for IDB $\mathrm{s}$ ber including all the inherent ramifications for scientific competence. This general purpose, understood 
in the context of the long-term economic and social development of these countries in an increasingly globalized economy, is fully consistent with the IDB's mandate for the coming years. For example, in section 14 of the Plan of Action of the Summit of the Americas held in Miami in December 1994, the governments of the Hemisphere referred to a series of needs in science and technology. The Appendix to the document specifically urges

in this field. The Hemispheric Meeting of Science and Technology Ministers, held in March 1996 on the mandate of the Summit of the Americas, issued the Cartagena Declaration which repeatedly refers to IDB financing and the need for the Bank to increase its support for the countries in this sector. The Report on the Eighth General Increase in the Inter-American Development Bank refers expressly to technological change as a factor in international competitiveness (paragraphs 1.16, 1.27, 1.29) and modernization of production structures (2.35, particularly subparagraphs (b), (c) and (f). The docum initiatives of its borrowing member countries "to advance technological development in the region" (2.35 (b)).

The level of $S \& T$ effort in the countries of Latin America and the Caribbean has been considerably lower than their level

economy. While the GNP of the countries of the region accounts for about $6 \%$ of th

producti

of the total. Some countries have been able to achieve considerable complexity in their industries and to export high value-added products. However, their scientific production has not kept pace, much less their technology generation. A country like Brazil, which has the world's tenth-ranking economy, invests just $0.7 \%$ of GNP in R\&D (compared to $1 \%$ to $2.3 \%$ in newly-industrialized countries), produces only $0.646 \%$ of articles published in leading scientific journals (Israel, with a population of 4 million, produces $1.074 \%$ ) and fewer than one eighth of the number of patents registered in Taiwan (the S\&T indicators are taken from Gibbs, W.W, 1995; CYTED/RICYT /OEA/MERCOCYT, 1996; International Institute for Management Development, 1994). The low levels of investment and efficiency in S\&T will have a negative impact on the region's future. It is clear, therefore, that a major effort is required in this area to invest more and to use those investments more effectively.

B.

The national innovation system

To a

countries today must have an institutional system that includes universities, $R \& D$ centers in businesses, information and extension agencies, institutions for financing, quality standards setting and control, consulting firms, technical-service laboratories, government regulatory agencies, and other institutions that interact in a broad range of activities running from the birth of an idea to its general use in society. If this system is nonexistent or very weak, a country is not capable of adequately selecting, absorbing or managing foreign technology, much less making its own efforts to adapt it or develop new products and processes. The weaknesses of such agencies and their linkage, or what has been called the national innovation system (NIS), ica and the Caribbean have still not been able to internalize technological change sufficiently.

Therefore, the core of an effective strategy will be the strengthening of systemic capabilities. This does not refer only, or even primarily, to public sector activities, but rather to public cooperation with the other sectors to unleash and support the creative forces of society, thus creating a general climate that encourages innovation.

C.

The role of the State in science and technology

The State is an agent for science and technology and an inevitable part of the picture: it sets poli- 
cies, finances a large part of NIS activities and, to a lesser extent, also executes them. The challenge is not to eliminate it altogether but to adjust its involvement appropriately in order to capitalize on its assets and confine its weaknesses.

\section{Only governments ha}

determine national policies, and the absence of explicit policies on S\&T frequently leads to ineffective and specious reasoning that ignores the collective interest. The general regulatory framework of each country and its public policies as a whole have a strong influence in $\mathrm{N}$

on the creation and maintenance of a climate that favors innovation. We will return to this later in the section on orchestrating the system. The State is a major source of funding for $S \& T$ in rich and poor nations alike, and in the latter it must play the principal role for some time, owing to difficulties in persuading businesses to invest in this area. Governments are often directly involved in implementing S\&T activities in vir

is an area in which there is greater scope for using alternative mechanisms. As a general rule, it is accepted throughout the world that governments should finance, althoug science and technology activities.

The need for government financ where the State's field of action is very narrow can be explained by market failures which necessarily lead to insufficient funding for different types of science and technology ac known studies on this subject by Arrow, K., 1962, and Brooks, H., 1986). Sometimes it is a question of producing public goods, such as basic knowledge that is not directly or immediate nomic activities but is indispensable for building science that

it is a question of producing mixed goods, in other words, goods with public interest components which in themselves justify government action and private interest components that can benefit from public investment. Private R\&D frequently creates exter- nalitie

cannot be appropriated by the persons who made the effort and incurred the costs and risks of $R \& D$ projects. In these cases, the social returns from such projects are higher than the private returns to the decision-makers. There are other practical reasons that frequently make the market fail to allocate resources for activities of this kind, which have to do with scale, long lead-times and excessive risks, and imperfections in the financial market that will be discussed later.

\section{Governments have a strong presence in financing} $S \& T$ even in countries that place the most trust in the operation of the market. Consider the case of the developed country that is ideologically the least inclined toward government intervention in the market. In the United States, agricultural research which led to huge increases in productivity has chiefly been financed and largely carried out for over a century by the public sector. In the industrial sector, there are no fewer than 12 federal agencies implementing programs that distribute subsidies for $R \& D$ to private industry, such as: (a) the Small Business Innovation Research Program which provides $\mathrm{R} \& \mathrm{D}$ subsidies to businesses with 500 employees or less; (b) the Advanced Technology Program for the development of generic civil technologies; (c) the Independent $R \& D$ Program to strengthen the $\mathrm{R} \& \mathrm{D}$ capacity of strategic suppliers; (d) the Technology Reinvestment Project for the development of dual-use technologies. The R\&D programs in defense, energy, and space exploration have had many dual uses in the past. For example, the radical innovations in radar, the first atomic reactors, certain special materials for aircraft construction, the first electronic computer (ENIAC), and satellites were developed with federal funds, but gave an enormous competitive advantage to private American corporations. All this, of course, is in addition to pure research financed by the National Science Foundation and biomedical research conducted and financed by the National Institutes of Health. As a whole, the American public sector spends around $1.5 \%$ of GNP on R\&D and the private 
sector a further 1.4\% (Branscomb, L., 1995; Fusfeld, H., 1994; Mowery, D. and Rosenberg, N., 1993).

A distinction should be drawn between "traditional" and "impartial" industrial policies. Traditional industrial policies that preselected industries (automotive, electronics, for example) to orchestrate long-term cooperation between the government and the private sector, and even picked some firms as winners in the market, appear to have fallen into disuse. There can be no doubt

precisely that for long peri

R\&D subsidie

ment contracts, and a series of open and hidden protection on the domestic market from foreign competition (Odagiri, H. and Goto, A., 1993; Kim, L., 1993; Frischtak, C., 1992). The development of the Airbus in Europe and the Sematech Program to strengthen the competitive position o tor industry in the United States appear to be recent cases of the survival of traditional industrial policies. However, policies of this kind should not be confused with government support for technological innovation that is more or less $i$

In the traditional approach, all the activities of certain businesses or industries are supported to turn them into winners; in the second, a type of behavior is encouraged in all branches of production.

Aside from the indisputable role of the State in pure science, there are examples of direct government support and financing for private technological innovation in Canada (Mullin, J., 1995), Denmark (OECD, 1995), France (Chesnais, F., 1993), Germany (Keck, O., 1993), Great Britain (Walker, W., 1993), Japan (Odagiri, H. and Goto, A., 1993) and other countries such as Australia, Israel, Italy, Korea, Spain, Sweden, and Taiwan. The arguments made by governments to justify their financing for national $\mathrm{R} \& \mathrm{D}$, which were summarized earlier in the discussion of market failures, are no less applicable in Latin America and the Caribbean. In this connection, the region can learn a lot from history and from real data from developed and newly-industrialized countries.

A recent work inspired in the structuralist perspective that has arisen in Israel (Teubal, M., 1995) suggests some avenues that are particularly pertinent for Latin America and the Caribbean. In countries where there has never been a market for technical and financial services for technological innovation, the development of those services cannot be left to the market, since the necessary technical and management capacity does not exist. Governments are called upon to cooperate with the private sector in creating supply and demand for that market, and this implies a learning process in society where public policy acts as a catalyst. Denial of this need is an ideological trap that paralyzes underdeveloped countries, makes them vassals to the outside world, and keeps their levels of private spending on $\mathrm{R} \& \mathrm{D}$ low.

On the positive side, the transformation of the business community taking place in the region and the concomitant growth in management capacity are elements that favor an increase in $R \& D$ in private enterprise (Waissbluth, M., Testart, E., and Buitelaar, R., 1992) and makes government action more effective. However, government action is not "doing" S\&T activities but rather guiding, supporting and financing them.

\section{D.}

\section{The linkage between S\&T and business}

The units that produce goods and services, i.e. businesses, should be the main players in the process of technolo

tions come from other institutions, they must reach businesses and be adopted by them or the results are inconsequential. The process is complicated, slow, and difficult, and many atte

successful. For example, for each drug that is pro

test many thousands of alternatives. However, the few successes that turn into real production amply justify all the efforts and spending on R\&D in devel- 
oped countries. There are good examples of this in the region as well. To mention just one case, the annual production increases resulting from the new varieties of soya developed by Viçosa University in Brazil are probably equal to that institution's total budget since it was founded close to half a century ago.

\section{Accordi}

ture on technological innovation (Nelson, R. and Rosenberg, N., pioneering wor

tion of products and processes that are new for businesses." It is this type of technological innovation, much more than radical innovation (Diebold, J., 1991), that lends

ity of the bulk of companies in a country. Also included are the so-called "soft" technologies, such as those of total quality, process reengineering, marketing, management control, and others that are even simpler but can be novel and productive for certain types of enterprises.

A large number of businesses in the region are very small (microenterprises and SMEs) and generally operate with primitive technologies and low productivity. Without issuin

area th for example, David, P., 1986), there is a clear need to pay more attention to mechanisms to disseminate existing technologies, such as information systems, personnel training, consulting and technical-assistance services, sectoral technology centers, recruitment of young ing, subcontracting and the formation of clusters, the purchase of licenses and patents, forms of linkage with multinational corporations (strategic alliances, joint ventures, supplier and client relations), efforts to adapt foreign technology and the whole technology support infrastructure (Dahlman, C., 1995).

As will be seen later, the indiscriminate dissemination of unadapted technologies can worsen the social problems of deve some countries that have been successful in disseminating technologies among small businesses, such as Israel and Taiwan, seems to indicate that the process of selecting and making effective use of foreign technologies requires significant national capacity to adapt them and ongoing R\&D is needed to maintain competitiveness. In other contexts, it has been empirically shown that companies and countries that perform more R\&D are able to use the technology developed by others more quickly and effectively; this suggests that the ability to identify, imitate and adapt new technologies is not a mere byproduct of that activity but one of its purposes (Mansfield, E., 1986). Also, the cost/benefit ratio for technology dissemination varies depending on the absorption capacity of the context into which technology is transferred (Trindade, S., 1980), and that capacity depends, in turn, on levels of education and R\&D.

In developed countries, businesses themselves frequently put up over 50\% of national investment in $\boldsymbol{R} \& \boldsymbol{D}$ (Nelson, R.R., Ed., 1993). The percentage is $78 \%$ in Japan, $64 \%$ in Germany, $61 \%$ in Sweden and 55\% in Canada, with levels somewhat lower than $50 \%$ in countries with large spending on military R\&D such as the United States, the United Kingdom, France, and Israel. In Korea, the percentage rose from $32 \%$ in 1971 to $80 \%$ in 1987, while the economy grew very quickly, and the ratio of spending on R\&D to GNP rose from about $0.3 \%$ to close to $2 \%$ over the same period (Kim, L., 1993). The case was similar in other East Asian countries (Chamarik, S. and Goonilake, S., 1994), particularly Taiwan (Hou, C.M. and Gee, S., 1993). In all the countries mentioned, total spending on $\mathrm{R} \& \mathrm{D}$ accounts for between $1.5 \%$ and $3 \%$ of GNP.

One of the thorniest problems today is the low level of $R \& D$ effort in Latin American and Caribbean businesses. No country in the region invests $1 \%$ of its GNP in R\&D, and the private sector does not finance more than 20\% (CYTED/RICYT/OEA/MERCOCYT, 1995). This makes it impossible to compete on world markets offering high 
value-added goods and services. One of the main lessons to be learned from world experience in this area is that public R\&D can support, but not replace, the efforts of companies themselves, particularly in the industrial sector (Fusfeld, H., 1994).

The question of why private $R \& D$ efforts have been so weak in the region is central. The answer appears to be a combination of factors: lack of incentives to innovate in overprotected markets where there is no competition and the type of business culture that this creates; obsolete legislation on intellectual property rights (patents, trademarks, copyrights etc.) and difficult processes for registering and administering them; and factors that affect investment levels and the general economic climate of a country such as inflationary policies and political instability. However, these situation are less prevalent in the current Latin American and Caribbean context. What seems to have survived is that the economies of the region have still not gone through a dynamic $\mathrm{R} \& \mathrm{D}$ learning process, and there are no technical or financial services markets for innovation.

E.

\section{The interface between science and technology}

From the conceptual standpoint, science supplies technology with an understanding of the real world and technology places scientific progress at the service of humanity. Accordingly, they are strictly complementary. However, in the process of building up mature S\&T institutions in the region, there has been a tendency to confuse the two spheres (particularly in universities), using the same rules and models for technology management as for scientific work. When this happens science can trap technology rather than foster it.

Science produces written works that are freely disclosed and predominantly target scientists with profiles similar to those of authors. Technology development may pass through written stages, but it is fundamentally concerned with productive results, in other words, the seed planted and harvested in the fields rather than the article published on new varieties. The targets of tec

not scientists but economic agents who must make decisions regarding the production of goods and services and do so on th

or, i

matic criteria of effectiveness. In the real world of $\mathrm{t}$

publ

writing but sold, bought, and used commercially.

There

dist

mission of scientific knowl

narrowly focused on institutions of higher learning; those activities move at a different pace and respond to motives that are generally different from those that drive the world in which goods and services are pro

each must be respected so as to avoid the lack of eff

fused. For example, the academic world is not normally the best place for developing a continuous flow of small technological innovations that are incremental in nature; this is something that can be done much better by the very units of production that use the technology. Certain countries in the region (Argentina, Brazil, Chile) have therefore developed specific institutional and financial instruments to advance technological development (FONTAR, FINE

the old national science and technology councils that have traditionally had closer ties to academics and $\mathrm{u}$

\section{It has generally been thought that science precedes} technology, in a linear model in which basic research produces new scientific knowledge, applied research transforms this knowledge into new products and processes in the laboratory, and experimental development continues this effort until designs and procedures are ready for implementation in given economic contexts. This model likely arose from certain well- 
known historical experiences. For example, the basic laws of electromagnetics were discovered (1831-1873) well in advance of the first commercially significant applications of electricity (1876-1900); nuclear physics was quite developed (1911-1932) when the first reactor was built (1942); and the discovery of the molecular structure of deoxyribonucleic acid (DNA) (1953) gave rise to a new scientific discipline (molecular biology) 20 years before the first atte

(1973).

The above notwithstanding, there have been times when technology preceded the science that explains it. For example, thermodynamics arose after (and chiefly to explain) the steam engine; aerodynamics was mainly developed after the invention of the airplane, and solid state physics gained momentum after the first transistor. They all helped in the subsequent perfecting of the respective technologies. Technology also develops instruments, such as microscopes, telescopes, oscilloscopes, computers, and magnetic resonance imaging devices that are later used in research and the development of knowledge, in a continual process of feedback between science and technology that makes the frontiers between the different disciplines and the different forms of $R \& D$ increasingly blurred.

One noteworthy example of the interdependence between science and technology is the laser (light amplification by stimulated emission of radiation). The theoretical possibility of what this apparatus does had been clearly foreseen by Einstein, but his prediction was not empirically proven until 1960. The manufacture $\mathrm{o}$ decade led to the technology of fiber optics as a means of transmission in the following decade and to a substantia

in inte

of often unsuspected applications in telecommunications, clinical medicine and surgery, stereophonic sound, precision measurement, defense and other fields that could include construction of the informa- tion

computer, which would have a much greater capacity than today's supercomputers.

In contrast to linear interpretations, models have been designed that explain the relationship between the development of science and technology in terms of parallel but strongly inte activities at all stages (Kline, S.J. and Rosenberg, N., 1986). These activities contribute to the pool of knowledge on the one hand, and develop new products and processes or new designs on the other hand. In these new models, a scientific discovery can affect any

from the very conception of what is possible to produce to the small but significant details of a final design that give a product a comparative edge on a market. Similarly, any stage in technological innovation may require assistance from the scientific infrastructure, in the form of specialized consultations of the pool of knowledge, or the generation of new knowledge, or the modification of existing knowledge when it is unable to resolve the problem. The above appears to indicate that the process of innovation is not linear and resembles a web more than a chain (Holm-Nielson, L., Saliba, A., and Crawford, M., 1995).

In light of the above, two basic flaws can be detected in many of the region's universities: (a) they have not been effective in providing a pool of knowledge or a support structure for the whole process of innovation; and (b) they have not educated the types of people who are indispensable for that process. In many cases, the problem was that they had no capacity for either of the two. In other instances, they did not form part of the grid of interactions for innovation, and sought instead to be the first link of the chain that would lead the productive apparatus along the supposed linear sequence between science and technology. Companies did not demand much of universities either, and governments did not play an active role in encouraging innovation. 
An overview of S\&T in the region seems to confirm what many have observed. Latin America and the Caribbean are lagging far behind the developed and newly-industrialized countries, although in the most advanced countries in the region the growth and maturity of science have been somewhat more significant than their achievements in technology. In some countries, fairly productive groups of scientists have been established as well as critical masses in certain areas of particular national or local interest. The technological results do not reveal the same degree of progress or maturity. However, modest results should not be confused with no results. There are a good number of successful cases of technological development in the region (see for example the 100 innovative companies studied by Waissbluth, M., Testart, E., and Buitelaar, R., 1992) and all indications are that sound policies in this field can have a decisive impact. In absolute terms,

to make a much more strenuous effort in both science and technology, but in relative terms it must push harder in technology than in science.

\section{F.}

\section{The links between S\&T and education}

There are areas in which national S\&T and higher education systems coincide closely, but both have their own problems that should not be confused, since the solutions may lie in different institutional environments and require different types of policies. Specifically, the problems of the governability of higher education institutions and the questioning of the social equity of subsidies for university students are not science and technology problems, and it makes no sense to hold back the development of society in the latter sphere because the problems in the former have not been resolved.

Despite this, the quality of education on all levels seems to be one of the most basic requisites for $S \& T$ development in any country (Eisemon, T.O. and Holm-Nielsen, L., 1995; Corona, L., 1994; Bailey, T. and Eicher, T., 1994; Brunner J.J., 1990;
Schwartzman, S., 1988; Rama, G., 1987; Pettit, J.M., 1986; Kennedy, D., 1986; Vessuri, H. and Díaz, E., 1985; Lavados, M.J., 1979; and Malek, G., 1979).

Good quality primary and secondary education makes the work force more trainable in modern techniques, using new technology in the production of goods and services. Abundant literature (summarized in CEPAL- UNESCO, 1992) has demonstrated that "education and knowledge" constitute the "keystone for productive transformation with equity." In other words, $\mathrm{t}$

significant factors that determine the productivity and competitive advantages of countries (see also Cáceres, L.R., 1994), and good education for all tends to prize human labor and to improve income distribution.

Higher education determines the quality of the main resource that generates $R \& D$ and productive activities with high value added, in other words, scientists and en

a large $\mathrm{p}$ interdisciplinary masses of resources which are generally the best in the country, affects the whole atmosphere in which science is produced and has an impact on the performance of other levels of education. Universities can directly play an important role in technology development, as the land grant colleges did in the agricultural sector in the United States. The direct links between universities and companies (Abeledo, C., 1990 and 1985) and some of their most modern manifestations, such as technology parks and technology-based business incubators, are receiving a great deal of attention in many countries (NSF, 1995; IDB/SECAB/CINDA, 1990; Waissbluth, M., 1988) and in the Bank as well (Iglesias, E.V., 1995). This is particularly relevant for Latin America and the Caribbean, where certain institutions of higher education account for a large share of all research capacity in their respective countries. 
G.

\section{Links between S\&T and employment and social development}

Since 1811 when the Luddite movement of unemployed workers in England began to destroy textile machinery, popular wisdom has identified the development of technology with the loss of jobs, which also has intellectual roots in the writings of Ricardo and Marx. While it is true that technological progress saves human specific categories of jobs, it is also true that it gives rise to new economic activities with more productive jobs that did not exist before. Furthermore, when the elasticity of demand with respect to the price of a product

required to prepare a single unit of the finished product can inc

in that production line through the effects on prices and the total volume produced, as was the case in automobile manufacturing after Ford introduced the assembly line (Rosenberg, N., 1986). Volume can also increase as a result of general increases in income and demand stemming from econo

The critical issue for a region with an abundance of labor and relatively scarce capital is whether the particular type of technology development it adopts will increase total employment or not, and to what extent. Indiscriminately

generated by developed economies with different endowments of factors can have detrimental effects on total em

example Sen, A.K., 1972). Some scholars have argued that the creation and adaptation of technologies geared to the inputs, markets, scales, and production resources of developing countries and to the solution of their social problems, particularly unemployment

opment intended to meet the basic needs of the population (see Ventura A., 1996).

This does not mean that the so-called "appropriate technologies" or "labor intensive technologies" are always the best for a country with an abundance of labor. Sometimes technological development makes all forms of production, except for one or two, "technologically inefficient," in other words, requiring more resources of all kinds to produce the same quantity. What has been known for some time is that the capacity to be highly selective in the choice and use of technologies distinguishes developed from underdeveloped countries. This is pertinent for the problem of unemployment, since the greater $\boldsymbol{a}$ country's capacity to select, adapt, and develop technologies that are genuinely appropriate, the less likely its social problems will worsen as a result of greater unemployment caused by technology (Mayorga, R., 1978).

Although the relationship between S\&T and employment is not unambiguous, the links between it and social development are clearer. Scientific and technological progress generally has a beneficial impact on the satisfaction of the basic needs of the population of any country. In Latin America and the Caribbean, development in this field could for example: lower the cost of construction materials for housing and make the latter more resistant to earthquakes; improve early childhood education and learning in primary schools; increase food production and enrich the basic diet - as has happened to some extent, but not sufficiently, in many countries. Science and technology may find appropriate methods for the prevention and treatment of diseases that are almost nonexistent in developed countries but which affect millions of people in the region, as has begun to happen through the work done in Colombia, Venezuela, and Brazil on malaria, leprosy, leishmaniasis, and Chagas' disease, among others. DNA tests are becoming crucial in the administration of justice. There can be no doubt that all these aspects merit support and promotion.

Biotechnology promises truly revolutionary changes in the twenty-first century, and this is important for the region for various reasons (Bifani, P., 1988). First, its impact on health and nutrition 
will probably affect everyone with regard to food types and availability, medicines, and therapeutic and preventive treatment, at the very least. Second, it is not sufficient to import generic technology because the range of specialized production and market niches is, in this case, as broad and varied as life itself. That and the unfolding of knowledge and production methods explains why no worldwide production structure exists in this area with giants that dominate markets (the oldest biotechnology company, Genentec, is much smaller than any of the leading companies in computers or microelectronics). Third, biology is probably the scientific specialty in which Latin America and the Caribbean has the greatest research capacity and experience.

Therefore, biotechnology is fully pertinent to the region's problems and their solutions, and for the first time in the history of the world technology revolution, some counties in Latin America may not lag so very far behind the developed countries if they make sufficient efforts and investments. This would give them advantages in identifying and capitalizing on specialized niches; it would also allow them to surmount barriers based on te general to negotiate with the outside world (licenses, patents, etc.) on a more equal footing.

\section{Information technologies}

ing the State and boosting the efficiency of virtually all public services, aside from being a generic technology used in a broa

processes. Access to information and the ability to use it to one's own advantage is a factor in the empowerment of the poor, in order above their condition (Ventura, A., 1996). Properly used, information technolo alleviate poverty and to strengthen organizations.

With spe ers are being used increasingly in education to support the learning process, as a key tool in finding and using pertinent information and to communicate and interact with other students and teachers anywhere. There are encourag

at all levels of education, including primary schools, as in the case of Costa Rica. The impact on education $\mathrm{o}$

aspect

glimpsed today (Stahl, L.G., 1996; Hamm, I., 1996). There are those who think that current education systems are fundamentally irreformable unless parallel systems are developed to transform them, and that is precisely what could begin to happen now $\mathrm{u}$

H.

\section{The international interface}

The two sides of the international interface are protectionism and cooperation. Self-sufficiency no longer makes sense today, when even the countries of the European Community and the giant multinational corporations join forces to cooperate in different areas of science and technology development. It is therefore difficult to imagine that Latin America and the Caribbean, with their scant resources, could do without international cooperation. However, technology is a commodity that is bought and sold, and even the countries that are the staunchest defenders of free trade are protectionist when it comes to some cuttingedge technologies. While attempts to create strict market reserves have led instea

lack of competitiveness, the region should not ignore the serious disadvantages that its companies face in this field with respect to their competitors in the developed world. Judicious government support for

$t$ companies is frequentlynecessary to enable them to develop technologically in a reasonable time and compete on interngional markets with some likelihood of success.

The international dimension of $S \& T$ has been given an extraordinary boost by the development of communications and information technologies (Gates, B., 1996; Hafner, K. and Lyon, M., 1996; Vitro, R.A., 1996). International interaction occurs 
with fewer restrictions in the case of science, but even in technology explosive growth is taking place in exchanges associated with economic globalization and multinational corporations. Too much stress cannot be laid on the importance for all countries to be connected to international interactive networks, since if they isolate themselves, they will be left on the sidelines of most progress in science and technology elsewhere in the world.

There are some promising programs in the region for international cooperation in this field. The Bolívar Program, inspired by the European program EUREKA, helps to link entities in the different countries of the region in joint projects to introduce or capitalize on technological progress in the production of goods and services for the market. At least one of the entities must be a company, but the other could be a university, which would thus foster international cooperation between universitie

ENLACE system under the Bolívar Program is a network of interconnected national offices throughout the region, which identify and bring together potential partners in a project and provide them with services to facilitate the materialization and development of their joint undertaking. Established in 1992, the program has aroused considerable interest in the region and has promoted dialogue among stakeholders in the countries and across borders (Bolívar Program, 1994).

Other commendable efforts have been made in cooperation among the Latin American countries (Waissbluth, M., 1996; Martínez Pavez, C., 1996) including in particular the CYTED Program (Secretaría General del Programa CYTED, 1996), which has organized the most extensive S\&T network in the Ibero-American countries since it was established in 1984. An innovative $m$

being prepare

the IDB a

n

agricultural research and provide more stable financing for it. The program, known as the Regional Agricultural Technology Fund, was agreed upon in March 1996. Sixteen countries are participating in it with active support from the IDB.
In December 1994, the presidents of the Americas noted the need for hemispheric cooperation in S\&T and $\mathrm{t}$

the matter in the Cartagena Declaration of March 1996. The governments of Central America have also referred repeatedly to this issue (Doryan, E., 1990; D

actual cooperation in this area is still quite modest in the region. An ambitious regional strategy is called for to help close the gap between the developed countries and Latin America and the Caribbean (Mayorga, R., 1989; Martín del Campo, E., 1989; Sagasti, F., 1988; Marcovitch, J., 1988; Herrera, A., 1987) and also the gap within

b

purpose but also, and above all, to attract more f

\section{I.}

Orchestration of the technological innovation system

In Latin America and problems with the splintering of capacity and lack of cooperation among development agents businesses, institutions of higher learning, research and extension, S\&T service providers, banks, regulatory

a

rate, to the detriment of both. Research units and projects tend to be minuscule and of little significance for economic activity, economies of scale are not generally present, and sufficient attention is not paid to the lack of critical mass. Public policies with an impact on science and technology development are rarely coordinated (see the international evolution of S\&T policy concepts in this field in Urquidi, V., 1988).

The two aspects which appear to have the greatest influence on innovation in the national economic t climate are the existence of competi with the outside world. Past experience indicates quite regularly that where the spur of competition from other suppliers is missing (the "invisible foot," Weiss, C., 1992), there is generally not sufficient 
motivation to improve the quality of products or the efficiency with which they are produced. Put another way, it is necessary to establish a general economic climate that demands competitiveness as a prerequisite for the success and even the survival of businesses, although this can be done gradually to avoid the trauma of the sudden closure of factories and the resulting mass layoffs. In an atmosphere of competition, there is natural growth in the demand for all elements that can increase productivity, including innovation based on the application of knowledge and related activities such as the updating of company personnel, $R \& D$, and scientific and technical services. On the other hand, most world science and technology development occurs outside the borders of any nation, which is even truer for smaller and poorer countries. Therefore, links to the outside established through trade and investment, staff training, and scientific meetings and cooperation, among other things, are generally the largest source of technology change, although this depends on the absorption capacity of a country and other internal conditions.

Some aspects of the general regulatory framework of each country and the specific economic policy instruments that should be examined in light of their possible impact on technology development are: (a) legislation on intellectual property (copyrights, patents, registered trademarks, licenses, etc.) and its management, which can facilitate or obstruct the international flow of technology and R\&D activities by businesses; (b) import duties, which may be used to lay the groundwork for competition or to protect certain local sectors and industries; (c) government procurement, which has been used in many countries as a mechanism to ensure a local market for given products and as a way of making it possible to build up technological capacity that local businesses would not otherwise have; and (d) financing mechanisms, which are examined in another chapter of this document. The potential fo

S\&T d explained earlier, and also on policies that can encourag

tural policies.

With regard to procedures for better linkage of the national technology innovation system (NIS), one recent study (Trindade, S., 1996) stressed the importance of prom $\quad \boldsymbol{a}$

all the countries of the region, as a way of producing shared visions of the future that will lead to "miss application of S\&T to specific development challenges. A "bankable portfolio of projects" wr result from these agendas, and it could serve as the basis for focusing support from the IDB a i

agencies. This approach is seen as a complement to market mechanisms and other instruments for setting national priorities, which would help build the social consensus that is important for the effectiveness and continuity of S\&T policies.

The institutional barriers that stand in the way of more $\mathrm{h}$

sur

Weaving the parts together to form a whole cloth is one of the most crucial aspects of S\&T policy in the region, because national capacity does not depend on a single type of factors or institutions, but it instead arises from the synergy between the different components (Oro, L.A. and Sebastián, J., 1993; CINDA, 1

attained in the past, but needs to be substantially improved in the future. It also demands that the governing agencies be given the resources they need to effectively promote and orchestrate the system. A n

system as a whole an

short, what is needed is a systemic approach that strengthens the key elements in the national innovation system in each country and the principal interactions among those elements. 


\section{-III- \\ Science and technology in small countries}

The sweep of the issues linked to science and technology policy has led some observers to note, not without cause, that the subject lacks focus and appears to be a jumble of bits and pieces. Furthermore, the difficulty of the issues to be addressed has frequently meant that they have been ignored, which has led governments to act in an improvised and incoherent fashion, or resulted in so-called "implicit" policies that often are simply

no $\mathrm{r}$

quences. In the case of small countries of the region, the situation is generally worse since, apart from the greater strictures they encounter owing to their size and poverty, it is less clear what they can and should do, how they should do it, over what time frame, and with what resources. Very little attention has been paid to the problems of these countries in the literature on science and technology policy, and this is part of the problem of the growing gap inside and outside the region that has been so often been pointed out.

The definition of a small country is to some extent arbitrary and depends on the interests of the definer. Some studies (Forsyth, D.J.C., 1990) estimate that size ranges can be established with significant links to the economic and technological variables of countries. Based on such studies, a recent work (Trindade, S., 1996) proposes a limit of a population of 10 million for the definition of smallness; however other authors writing on S\&T (Freeman, C. and Lundvall, B.A., 1988) include Canada among the small countries, obviously on the basis of other criteria. This study will focus on the IDB's Group C and D countries (Bahamas, Barbados, Belize, Bolivia, Costa Rica, Dominican Republic, Ecuador, El Salvador, Guatemala, Guyana, Honduras,

Panama, Paraguay, and Uruguay) which to date have received little assistance from the Bank in carrying out S\&T programs. None of these countries currently has more than 12 million inhabitants and their GNPs are not over US $\$ 30$ billion, although it is questionable whether some of them, which have ve tions but relatively high per capita incomes, such as Bahamas and Barbados, can be considered poor.

A.

There are various kinds of priorities for science and technology policies in any country, large or small. It is necessary to chose among different alternatives for the following, as a minimum: (a) subject areas for focusing efforts; (b) the types of science and technology activities that should be promoted (basic research, applied research, experimental development, training of researchers, basic science teaching, technical training for the work force, information, extension, consulting, metrology, standardization and quality control services, etc.); (c) time horizons for achieving given policy objectives; (d) types of entities or institutions to carry out the activities (universities, public research institutes, ministries, large, mediumsized and small international and local businesses, nongovernmental organizations, etc.); and (e) financial resources and mechanisms for obtaining and channeling them (direct government budgetary alloc

investments, loans, etc.).

Furthermore, procedures for priority-setting can also be viewed as part of policy-making (government planning, market without government intervention, dialogue among stakeholders, etc.) as can the measures on the regulatory framework and the climate which have a marked impact on the effectiveness of a policy itself (promotion of foreign investment, 
legislation on intellectual property rights, import duties, government procurement, etc). This area is truly complex owing to the number of interrelated variables and because "priority" is not necessarily exclusive, but could include different levels.

The smaller and poorer that countries are, the greater their internal resource and market constraints. This in turn further restricts their options and means that they must be highly selective (see the cases of Honduras, Jamaica, Panama and Uruguay in, respectively, Cruz, A. and Doryan, E., 1993; Ventura, A., 1991; Tal, E., 1985; and Arocena, R. and Bortagaray, I., 1996). It is not feasible American or

range of scientific and technological capabilities already available in Brazil and Mexico, with regard to the number and variety of human resources, specialized institutions and fields or disciplines where there is a critical mass for effective, high-quality work. Nor can the latter countries realistically aspire in the $\mathrm{f}$

diversification of available in the United States or Japan. Smallness and poverty are re both limit possibilities and require that priorities for actions and investments be set within a narrower range of options. There could also be some advantages assoc

cate

ease of communi

ment (Ventura, A., 1991).

B.

Fields of specialization

Agriculture and health are obviously priority candidates for the concentration of efforts in small and poor countries, owing to the wide variety of agricultural products and diseases specific to each country. The same holds true for environmental protection and natural resource management, the adaptation of industrial and service technologies, and the development of applications for generic technologies, such as information systems and biotechnology, that can be constructively used in local production processes without requiring large capital investments. We will return to the issue of selecting specific priority areas for focusing mediumterm investments.

Despite what has just been said about agriculture and health, small and poor countries appear to be caught in the trap of ineffective technol

in a context of pervasive scientific incompetence. What this means can be easily explained with a pair of examples. Something as apparently simple and aleady tbanleficial for some countries as raising agricultural productivity and improving nutrition by combatting corn viruses could require knowledge of molecular biology and other scientific fields, as well as a variety of research and development capacities that goes beyond the traditional experimental work done in most of these countries. This technology, like so many others, cannot be imported and applied locally without adaptation. Another apparently simple and clearly beneficial advance for tropical countries would be the development of an effective vaccine against malaria. But this has not yet been done in any country, large or small, with the probable exception of a vaccine that is still at the trial stage, developed in Colombia through a mammoth scientific effort headed by Dr. M.E. Patarroyo (Spurgeon, D., 1995).

Insistence on narrow technological specialization, without due attention to the scientific base for that specialization, tends to have the counterproductive effect of ineffectiveness in achieving the goal. This point has been made frequently in the literature on the subject (see Thulstrup, E.W., 1994, 1992; and Licha, I., 1995, among others) and is linked to the growing mutual dependency of different branches or areas of knowledge and the critical mass that is necessary for a country to make maximum gains from its investments in S\&T.

There is no simple formula for determining to what 
extent a country should invest in building up a more extensive capacity to work competently in a broad range of fields and areas or, on the contrary, focus its investments in specialties of greater immediate economic or social interest. The answers depend on the initial conditions in each country and particular needs in the areas in which it would be advantageous to specialize. What can be affirmed in a general way is that the countries must escape from the trap of dual scientific and technological weakness as quickly as possible, and this requires that each strike a judicious balance between investments in the two areas. The entire process of selecting fields of study and allocat i countries' own problems and the wish to address. This position stands halfway between the simplistic

of small infrastructure, whi that trap, and the irresponsibility of placing the general interests of science and scientists above the economic and social needs of the people of those nations.

\section{Determining which activities should be promoted is very}

the life of a country, five years of work in science and technology is the short term, five to 10 years is the medium term, 10 to 25 years is the long term, and over 25

tant simpl

this year, the answers will be very different from those arrived at when the time horizon is a decade. Therefore, the guiding thread is what can and should be done in different time frames, with discussion of the other pertinent variables revolving around that hub.

\section{C.}

\section{The long term}

\section{The long-term goal should be}

able degree of general scientific capacity, regardless of how dismal the situation of these countries is at present, and this chiefly requires continuing investments, however modest, at all levels of the education sy

these countries more as a necessary input for training creative professionals than a means of contributing to the world's store of knowledge (Thulstrup E.W., 1994, 199

country will have a minimum of basic skills in a broad range of areas than as a means of directly increasing its GNP.

Institutions of higher education are naturally specialists in professional training and basic research; the numben and variety of scientific regearchers in a country is closely linked to the institutional development of its universities. The criteria for evaluating higher education and basic research should be those traditionally used in judging academic excellence, and the main form of social control should be to internalize those criteria in the procedures and routines of the academic community itself (Castro, C.M., Levy, D.C., and Bernasconi, A., 1996). Other institutions are also important in boosting a country's general scientific capacity, including primary and secondary schools, work force training institutions, and others that help to popularize science as part of the national culture.

Almost all countries depend to some extent on training abroad in certain specialized fields, particularly small and poor countries in the early stages of building up their scientific infrastructure. Owing to the cost of advanced level scientific training abroad and the limited prospects for future income that graduates have in their countries of origin, this training is nonexistent or insignificant unless there is decisive organization and financial support from the government, which ought to tap the possibilities for cooperation in this field offered by other countries. It is also important to organize and bring back to the country citizens studying and working abroad in science and technology and to establish stable ties with centers or institutions that help those that are less developed through twinning or similar approaches. 
D.

\section{The medium term}

In the medium term it is necessary and feasible in any country to focus science and technology capacity on given areas that are strategic for national development. The selection of these areas is particularly crucial for small and poor countries which cannot afford the luxury of choosing too many fields. Such decisions cannot be left exclusively to market forces since, as was explained earlier, there are too many market failures that can turn into catastrophes where there is no market for S\&T activities at all. It is also very risky to allow the government bureaucracy to set priorities, which can change with the party in power and can be radically estranged from the country's true situation unless there is a broad process of consultation with those who will presumably be carrying out the decisions. Ideally, a process of reaching agreement among the main stakeholders is required, as was mentioned earlier in the section on orchestrating the NIS. A broad, clear and solid social consensus, periodically renewed, will result in the establishment of priorities that are more likely to be stable and effective.

In selecting strategic fields on which to focus capacity, consideration should be given to the scientific and technical skills necessary to: (a) add economic value to the country's main resources and products; (b) identify and capitalize on new specialized niches where the country can compete internationally; (c) meet the basic needs of the population better, particularly in the areas of nutrition, health, education, housing and employment; and (d) protect the environment and manage natural resources rationally. It was suggested earlier that in these countries the answers to these questions are generally found in agriculture, health, and the ecology, in adapting industrial and service technologies, and in developing generic technology applications. However, the responses necessary to act and invest in strategic fields are much more specific than that and vary greatly from country to country. While one country could focus on the production and processing of a given agricultural product, the focus of another might be the mining and processing of an abundant mineral, each obviously calling for different specialties.

\section{Applied research and experimental development are the keys to developing focused capacities in strategic fields. Different countries could have very different institutional arrangements in this regard. There is no special reason to assume that academic institutions are the best suited in this case, although sometimes they may be. Public non university R\&D institutions, nongovernmental organizations and different types of businesses and business associations can also work well for this purpose. In any event, it is important that the entities carrying out $R \& D$ are close to the users of the outputs, and that effective linkage between them exist.}

Some examples of successfully focusing applied research and experimental development capacity in small countries of the region are the Nutrition Institute of Central America and Panama located in Guatemala, the banana research facilities of the Honduran Agricultural Research Foundation, the Tropical Agronomy Research and Teaching Center in Costa Rica, the Gorgas Laboratory of Tropical Medicine in Panama, the Eric Williams Medical Sciences Complex in Trinidad, the National Center for Marine Research of the Coastal Polytechnical School in Ecuador, and the Clemente Estable Biological Research Institute in Uruguay. Two aspects of these centers are worth noting: several of them have been established to serve the common needs of a group of countries, and virtually all of them were founded with external support or have received ample international assistance.

The promotion of applied research and experimental development in businesses and other activities to create an innovative entrepreneurial climate are another medium-term objective that the countries can set for themselves. This is linked to the regulatory 
framework, the rules of the game, and the general economic climate. But the process must also be facilitated through technology development funds to provide financial support for businesses that take risks and invest in technological innovations. These funds should seek to multiply successful cases of innovation a spread from business to business. In other words, prime the pump and start up a process that would otherwise not occur or would operate too slowly in small and poor countries that have never had an innovative entrepreneurial culture. In some cases it might also be possible to establish semipublic risk capital ventures, as has been done in certain East Asian countries, to show the kinds of returns that can be had from investments in fledgling companies that are truly capable of developing new ideas.

E.

\section{The short term}

\section{In the short term the go} tion and rational use of existing world technologies of interest to a country. This is something that would obviously benefit many people and companies and does not generally entail excessively high costs, which means that the incentives are quite large. To some extent this occurs spontaneously through market mechanisms, particularly in the context of economic liberalization, contact with the outside world, and relative prices of the production factors which reflect their respective scarcities. The spur of competition, respect for intellectual property rights and stakeholders dialogues (Trindade, S. , 1996) are other important factors.

\section{The point here is not to do something that can be} achieved spontaneously, $b$

When over half the wood that enters a sawmill in a poor and small country is wasted because the machinery purchased was not

when post-harvest losses of agricultural products exceed $50 \%$, when a factory is built with a great deal of idle capacity because no one knew that there was a better and cheaper technological option, when a company attempts to export without being aware of the technical standards in importing countries, when there is no capacity to make even the smallest modification to a product so that it will be more competitive on a given market, or changes to a production process to reduce costs or increase efficiency, something is wrong in the country which is not the exchange rate, the interest rate, or the general macroeconomic climate.

What is almost always missing in this regard, in these countries, is the technology support infrastructure. In the developed countries, this infrastructure consists of a large number of entities that provide science and technology services such as registration, processing and supply of all kinds of information, specialized consulting services on technological matters (including management), short technical training and professional development courses, agricultural and industrial extension, metrology, microscopy, technical standards, quality control and certification and other services. These entities, together with educational institutions, businesses and $R \& D$ centers along with the agencies responsible for regulating and financing $S \& T$ activities, when they interact in a systemic way in society, constitute a country's national innovation system. say, this system is virtually nonexistent in small and poor countries. That is one of the primary reasons for their under-development

ing themselves adequately on the international scene.

\section{F.}

Strategic approach in the small countries of the region

The above suggests that what a small country must do in this field, like any other country, is to gradually build up a national innovation system. What varies among the countries of the region is how much time is necessary to develop an effective NIS, with its respective sizes and degrees of diversification, but not the nature of its core components. If universities are 
ignored and the result is a very weak supply of higher education, the foundation of the entire system fails since it is built on the country's specialized human resources. This, in turn, means that sights must be set very low over any time horizon. If the businesses that use technology in the production of goods and services are ignored, they will not be able to make a substantially larger contribution to satisfying the needs of th

tion between knowledge and its ap

tion does not operate well, separate and disconnected subsystems are established, each failing to tap the full potential of closer and mutually enriching ties which is the heart

The fact that the approach should be gradual must not be interpreted as an excu

and investments in medium- and long-term goals. Certain objectives can only be attained in a given period if they begin to be pursued steadfastly now and the effort is continued during the entire period.

An adequate national science and technology strategy should therefore include components to be executed during the life of an action and investment plan, but which will only bear full fruit after that term, with the same holdi

until the poor small country becomes a developed one. Afterwards, it will have to continue acting and investing in this field, but those stages will be of a somewhat different nature.

\section{A summary of the kinds of} suggested for small countries is given below, as an initial contribution to a difficult and largely unexplored area. A five-year $p$ strategy should be designed to build and gradually develop a coun nation of at least the following three types of investments: (a) relatively fast maturing components of maximum immediate use in the NIS, geared to str

for companies through $S \& T$ services for the adaptation, dissemination, and rational use of existing technologies; (b ing on applied research and experimental development that seek to foster innovation in businesses and establish fo and ada

fields of particular importance for the country; (c)

on human resource development in educational institutions at all levels and on basic research in universities, designed to achieve an acceptable level of general capacity in the country to cope with today's explosion of knowledge and its productive applications.

All the above assumes that the priorities and actions and investments under each program are very closely geared to the country's specific needs and possibilities. Also necessary is a strong national agency to coordinate and finance the effort, within a regulatory framework and general climate conducive to innovation.

There is nothing mysterious or unattainable in this approach. The S\&T programs being completed by the governments of Costa Rica and Uruguay with IDB support contain many of the elements suggested. The approach is not very different from what some small and medium-sized countries in East Asia have done in the last 25 years. The funding required for such programs over five years will not take anything away from satisfaction of the most basic and immediate needs of the population. Starting with very low levels of S\&T spending (less than $0.4 \%$ of GNP in almost all the small countries of the region), it should not be too difficult for an economy growing at several GNP percentage points a year to provide the resources needed to gradually increase this effort. 


\section{-IV- \\ Science and technology in large and medium-sized countries}

Just as we saw for small countries, the definition of large and medium-sized countries is relatively arbitrary and depends on the interests of the definer. Here, they are understood to be the IDB's Group A and $B$ countries (Argentina, Brazil, Chile, Colombia, Mexico, Peru and Venezuela). The dividing line between these and small countries is currently set at about 12 million inhabitants and US\$30 billion in GNP. Ecuador and Chile, which are closest in population to this

indicators. Ecuador is quite close in general to the smaller countries, while Chile, with the highest scient

in the region, is closer to the Group A and B countries. Some relatively small countries (Jamaica and Uruguay, for example) have per capita S\&T indicators that are better than several of the larger countries, but the size of their economies makes a significant difference in that it imposes very different strictures on the internal size and differentiation of their respective NIS. Some regions of the larger countries (e.g. northeastern Brazil, southern Mexico) have S\&T situations similar to those of the smaller and poorer countries, and much chapter applies to them.

A.

\section{Light and shadows in a motley picture}

Most of the larger countries in the region have generally gone through a process of building up infrastructure and basic capacity in this field, particularly from mid-cen

have some reasonably good universiti excellence in certain fields, to world literature in their respective specialties.
There is a relatively large and able body of professionals; the range of areas and fields with at least a few very highly-qualified specialists is quite broad and diversified. There are some well-equipped laboratories whose instruments are not obsolete; there are good libraries and an increasingly well-equipped information infrastructure. The $\mathrm{s}$

averages are much lower

but this is the result of very disparate situations in the region, where some researchers produce the equivalent of their colleagues in the first world and others produce almost nothing.

These countries also have extension centers, consulting companies specializing in a variety of areas, and agencies for standardization, metrology, and quality control and certification. Technological support services are more numerous and easier to find than in the small countries. A good number of businesses know how to effectively use advanced technologies and modify them to their own advantage. However, here ends this brief summary of the positive aspects of the general status of S\&T in the large and mediumsized countries of the region.

The physical infrastructure and equipment for $S \& T$ activities in several of these countries is too old, partly as a result of the financial crises of the "lost decade" that made it impossible in many cases to replace the existing base. In one institute, biologists trained at the Pasteur Institute and similar institutions were forced to work with equipment that predated the discovery of DNA. Yet this is the simplest problem in this field, when the human and institutional capacity for quality work already exists. It is merely a matter of spending, to the extent of a country's ability, to provide essential instruments and 
not museum pieces that reduce the performance of the country's best-trained people. The need for replacement and additions to infrastructure and equipment must be addressed by assigning the highest priority to cases in which investments will have the greatest impact on the adequate use of existing human capacity and which help most to at least conserve the core areas in which the country has achieved significant critical mass.

A more serious problem for these countries is generally low salaries and the uncertain or unstable situation of a large part of the scientific community, whose members are frequently forced to hold down several jobs simultaneous the problem has been addressed through salary supplements under a "national researcher system," which is more or less equivalent to establishing a meritocracy judged by the scientists themselves, or through a "research career" or project competitions that supplement wages, or similar mechanisms. However, much remains to be done to achieve a better match between the capacity of these people and the salaries they are paid

productivity that society has the right to demand of them and the recognition and stability it offers them. There is no magic formula for achieving this, but a satisfactory solution can be found to this basic problem which affects all the countries. It would require a measure $o$

members of the scientific community have a decent standard of living and a measure of support contingent on the results of their work.

B.

\section{What these countries need most}

What the largest countries in the region truly need is to make better use of their existing S\&T capacity to generate a much larger volume of innovations that are actually incorporated into the production apparatus and have a beneficial socioeconomic impact on the public. As world experience has shown, this cannot be done well unless there is a significant increase in R\&D investment by the businesses themselves.

Thi

document, but the following example will serve to highlight it again. In the countries of Latin America and the Caribbean, corporate spending on $R \& D$ is not more, in the best of cases, than $20 \%$ of total national spending, with the other $80 \%$ or so coming from the public sector and a modest contribution from abroad. Sou similar to that of Latin America in the 1960s, has attained precisely the reverse ratio, in other words, the business sector finances about $80 \%$ of national spending on R\&D and the government $20 \%$ (Kim, L., 1993). As a result, Korea grants more patents than Brazil, Mexico, and Argentina combined (The World Competitiveness Report, 1994). This technological vitality is undoubtedly one of the decisive factors in that country's extraordinary economic growth in the last 25 years. Furthermore, that growth has both permitted and demanded, in a continuing chain of causes and effects that feed into each other, a large expansion of all its scientific infrastructure and production. Korea's output of published articles was insignificant in the 1970s in comparison with Argentina, but today its total yearly scientific production is more than 55\% higher than Argentina's (Gibbs, W.W., 1995).

The point being stressed here is that the structure of S\&T effort in the largest countries of the region is badly out of balance and needs a fundamental correction to greatly increase the share put up by businesses in comparison to public institutions. As with all changes in the ratio between a numerator and a denominator, this could conceivably be achieved by increasing one or reducing the other, or through a combination of both. However, in this case it is not that public effort has been very high, but that private effort has been too low. In the same way as it is unacceptable to increase per capita income in a country by reducing the denominator through a larger mortality rate, countries that have already achieved 
some level of basic competence should take great care not to suffer a setback in this field by getting caught in the trap of "ineffective technological specialization in a context of pervasive scientific incompetence," as explained earlier. The solution lies in raising the absolute level and efficiency of public efforts in many areas of science and technology, including the most basic, and increasing the level and effectiveness of private efforts even more. How to do so is the crux of the issue for these countries.

C.

\section{Promotion of technological innovation in the context of globalization}

With a view to promoting changes or technological innovations in the private sectors of these countries, at least three different segments can be distinguished that require differentiated policies. The first is the large stratum of microenterprises and small production uni technologies with very low productivity, and virtually never employ persons who hold a university degree. Although this segment may produce innovation through a process of trial and error, it is not a major source of technological change today. The second stratum

consists of enterprises of any size that use cuttingedge technologies in the production of goods and services

per employee, and that employ large proportions of engineers, scientists, and management professionals. The third segment is a broad and somewhat blurred group of businesses that use intermediate technologies, typical of the more routine assembly line production of industrial society, with productivity that falls between that of the other two segments. It includes subsidiaries of multinationals that produce sophisticated articles usi

such as so

professional staff with some innovative capacity but to a much lesser extent than the companies in the second segment. In Mexico, for example, corn production wo segment, electrical materials in the second and textiles in the third.

The first segment has very little capacity of its own for innovation and what it chiefly needs are technical and scientific services for the adaptation, dissemination and proper use of existing technologies, similar to what was recommended for the short term in small countries. In this case, the effort the businesses would have to make is to absorb technologies that would appreciably increase their productivity and income. The accent is on personnel training, employment of professionals when possible, technical advice for the selection and startup of forms of production that are new for the businesses, small improvements in production processes to increase volume or quality, learning to comply with technical standards and to produce uniform products, introducing new accounting or management and marketing practices and, in short, incorporating the modern elements that are advantageous for these types of enterprise. The agencies that support them should have their own $\mathrm{R} \& \mathrm{D}$ capacity to be able to adapt technologies to the specific needs of clients. Where possible, users should be charged for the cost of these services, but there are instances in which the broader interests of society make subsidies preferable.

The second segment is, of course, the smallest, although in some countries it has more companies than is often realized. By way of example, in Brazil the Embraer company manufactures aircraft and sells them worldwide; Metal Leve is internationally known for the sophisticated automobile parts it produces using its own technology; Itautec competes with IBM and Compac for first place in the production and sale of computers on the local market, which has been unrestricted since the market reserve was eliminated in the early 1990s; Humana Informática develops software, sells it in many countries and has won prizes such as the Byte Award; the program for the promotion of Brazilian exports of software, known as SOFTEX 2000, is rapidly penetrating international markets; Consub develops and sells new types of 
robots for the maintenance of deep underwater platforms; Mapra exports microwave antennas built according to its own new designs; Zetax does the same with telephone switchboards and $C B V$ Indústria Mecânica with novel petroleum equipment; Quiral has developed new cancer medications; Nortec and Fiocruz (a public entity) new antivirals; Coopersucar new varieties of sugar cane through genetic engineering; and Termo Técnica has developed new production processes for protein concentrates using the effluents from breweries. Brazil's pioneering achievements in soybean varieties and alcohol as a fuel for automobiles are well known. The country also produces magnetic resonance imaging tomographs, new digital systems for distributed control and new applications for electronic holography, among other successful technological innovations (Magalhães, M.H., 1996).

Its international sales and the inputs it buys from different countries and other circumstances as well seem to indicate that this segment of cutting-edge technology companies is

as can be seen for example in the recent sale of Metal Leve to a German multinational group and the success of other companies that produce automobile parts, such as Iochpe and Cofap, which have followed a strategy of closer links with a broad range of international suppliers and clients. The same is suggested by the

of Brazil's computer companies and b alliances with world giants in microelectronics and information technology of the kind that Itautec has needed to compete on its own market.

It is possible that some companies in the region will be unable to survive in fields with heavy international investment in $R \& D$ and very fast technological change, unless they develop a strategy for alliances and joint ventures with multinational companies (Vonor creative high value-added activities to the region, aside from seeking their own niches to capitalize on what the giants do not do. In the case of this segment of companies, public policy should be to support and facilitate this strategy, with the specific assistance required in each case, and to establish and maintain general $\mathrm{c}$

availability of highly skilled human resources, laws and administrative practices regarding intellectual property (Frischtak, C., et al., 1996; Primo Braga, C.A., 1 country.

$T$

which makes it difficult to generalize. Assuming a competitive environment, economic openness and all the other features of a macroeconomic context and regulatory framework that favor innovation, many businesses in these countries need at least three things to become more innovative. First, the successful examples of other enterprises like them which show that innovation is indeed possible and profitable. This again points to the need to prime the pump and to the catalytic role of public policy during the innovation learning process, until innovation becomes a component part of business behavior and a financial and technical services market has been developed to support it. Second, the companies need financing under reasonable terms for their innovation requirements, since innovation is not a routine commercial activity. This need is discussed in greater detail in chapter $\mathrm{V}$ of this document. The businesses also need links to solid academic institutions that can provide them with a window onto the world of science and allow them easy access as often as necessary to specialized personnel, technical advice, professional development, and other services that can be offered by institutions that possess and continually deepen a pool of knowledge of all kinds.

\section{D.}

Putting together the puzzle of national innovation capacity

One main difference between the $S \& T$ situation in larger and smaller countries is that the latter (with some possible exceptions) need to establish or build 
up an NIS starting from the few solid components they have, while the former need to consolidate and integrate many scattered elements to enable them to produce the economic and social benefits that society expects as quickly as possible. There cannot be much innovative synergy where the core components of the institutional system that generates it are missing or are too weak. It is therefore even more important to boost synergy in the larger countries which have the basic components of an NIS than in smaller countries that do not have them. In one case, the house needs to be finished and moved into, in $\mathrm{t}$ tions still need to be shored up. In both cases, however, the final test of an NIS is whether or not the products competitively satisfy economic and social needs.

A country's NIS is like a puzzle with many pieces. If many of the pieces are missing or in the wrong places, it is impossible to see the whole and it does not consti

a systemic way it must

pieces must $b$

has been argued that the large and medium-sized countries

necessary for an NIS, but

puzzle, which is technological innovation in the businesses themselves. Furthermore, the mechanisms for linking the whole often leave much to be desired and must be considerably improved. This was dealt with earlier in the discussion on the orchestration of the NIS and the interface between S\&T and higher education. The linkage between universities and businesses (in view of where $R \& D$ capacity is concentrated in the region) is crucial for an NIS to take full advantage of existing capacity that is generally not well used. Technological innovation in companies of all sizes a

human resources that are trained in institutions of higher education and on the services that these institutions can and should provide directly to businesses, including in some cases advanced forms of this linkage, such as technology parks and business incubators.
The above points to several factors: the need to promote $\mathrm{R} \& \mathrm{D}$ and other technological innovation activities in businesses in a differentiated fashion, as has $b$

and $b$

have already attained considerable developme quality in their own functions; and the systemic articulation of the whole. These are precisely the missing or faintest pieces of the puzzle and therefore the most important ingredients in an appropriate science and technology strategy for this type of countries.

E.

The strategic focus in the larger countries of the region

A summary of the kinds of actions and investments suggested for the large and medium-sized Latin American countries is given below. A five-year national S\&T program should be designed to improve the consolidation and linkage of their NIS's to field significant economic and social benefits in the short term and increasingly greater benefits over the medium and long runs. The program should include a combination of at least the following four components: First, direct promotion of $R \& D$ and other technological innovation activities in businesses, including solutions to the problem of the lack of financing for such activities in enterprises that need money but cannot obtain it, which could take the form of the expansion and aggressive use of technology development funds. Second, linkage between universities and businesses to increase and improve direct services for businesses such as $\boldsymbol{R} \boldsymbol{\&} \boldsymbol{D}$ under contract, technical advisory services, professional development, and easily accessible windows on the pool of knowledge, which could also supplement the incomes of universities by diversifying their financial base. Third, consolidation of NIS institutions and solutions to other specific problems in some countries, such as obsolete physical infrastructure and equipment, highly qualified scientific staff in insecure situations 
and with salaries that are not compatible with the skills and dedication expected of them, and the shortage of specialized personnel in some fields of S\&T. Fourth, orchestration of the NIS, as explained earlier, but with the added factor that strategies in some cutting-edge technologies will probably have to be rethought owing to rapid internationalization and denationalization of local businesses. 


\section{$-\mathrm{V}$ - \\ Financing for science and technology}

Since the IDB is a financial institution, its activities focus on mechanisms for the transfer of funds. In S\&T operations, the Bank usually provides loans to national institutions which in turn transfer the funds to a number of individuals and entities that execute science and technology activities. Such activities include those which have traditionally been central in this field (R\&D and training for researchers) as well as scientific and technical services that use the same kinds of people and tools as R\&D but which do not generate new knowledge, products, or processes or modify existing ones. Some of the problems in financing these activities are discussed below, and different mechanisms that can be used to transfer funds to specific projects and executing agencies are suggested, pointing out the main advantages and drawbacks of each. At the end of the chapter, suggestions are made as to what the objectives and the typical components of a S\&T program financed by the Bank could be.

A.

\section{Problems with S\&T financing}

S\&T activities, and R\&D in particular, generally have a series of characteristics that make their financing quite complicated. First, in comparison with other activities, there is greater uncertainty about the outputs to be produced and their nature. What is sought is often not found, frequently something different is discovered, and sometimes unexpected results are

objectiv

in which the outputs of scientific and technical research can be applied to the production of goods and services and have a socioeconomic impact. Third, the results may generate different types of benefits, some of which accrue to individuals and entities that do not pay directly for them (public goods). This means that there are different degrees of appropriation of the benefits on the part of those who have made the effort and different degrees of externalities or benefits for others who do not pay. Sometimes there is a dual (military and civilian) use of the reseach outputs, or other public and private uses (mixed goods) and, at times, even though persons who do not pay could be excluded from given benefits, society decides not to do so (merit goods), since that is viewed as inappropriate or uncivilized, as typically occurs with some education and health services.

\section{There is one case in} be determined using relatively simple commercial banking criteria, aside from the instances in which the interested party can offer such extensive guarantees that the banks do not look at other aspects. This case exists when the scientific or technical outputs of an activity are clearly foreseeable, as is the time frame in which economic benefits can be felt, that term is not too long, the appropriation of the benefits will be sufficient to cover the costs of producing them, and there is a reasonable probability that the interested party will be able to obtain not just the scientific or technical result results as well. Even so, there may be practical problems with excessive guarantees required by banks, loans extended for terms that are not e compatible with the time required for the results to mature, and so on, but it is conceptually clear that financial agencies can deal with these cases more easily than any of the others in this field. However, a large part of R\&D activities carried out in any country, and many of the most significant advances, fail to satisfy all these requisites, and are therefore not generally financed by commercial banks. 
The above leads to the question of which activities should be financed with public resources and how. This issue has been considered theoretically and practically for many y

Brooks, H., 1986, for example) and therefore it is only necessary to briefly summarize some of the conclusions of interest to the present study. As for $\boldsymbol{R} \boldsymbol{\&} \boldsymbol{D}$, the cases where there appears to be a broad consen not necessarily execution, by government agencies, are: basic research and all research used by the government to carry out a function incumbent upon it $\mathrm{r}$

not; private $R \& D$ with strong externalities but which cannot pay for itself; and R\&D that increases or improves merit goods.

There is no scientific uncertainty in the case of science and technology services since they are not intended to generate new knowledge, products or production processes, but to apply and disseminate what already exists. Furthermore, the benefits of activities of this kind are generally highly appropriable in the short term by those receiving them so that, as a general rule, users should pay for their cost. Credit can be extended when users have difficulties in paying immediately or service providers do not have investment or operating resources immediately available. The exceptions that do require the use of government funds are services that carry out eminently public functions such as the establishment and enforcement of technical standards for environmental protection, the safety of food and medicines, and cases in which society has decided that some services are merit goods, such as agricultural extension services for small farmers in many countries.

The most controversial case is financing for higher education, which is a mixed public and private good. Students increase their income-earning potential to the point that the private appropriation of the benefits of higher education offsets its total cost in many fields of study. However, this is not true in some fields, part

and other researchers, which often provides great benefits to society but not to the direct beneficiary of the studies. Although it is difficult to quantify these characteristics in practice, the general solution points in the direction of charging the direct beneficiaries for the benefits they can appropriate for themselves, and using public resources to finance the externalities. Charges to the beneficiaries should be eased with facilities for postponing payment, such as student loans for those who need them.

The above is also recommended from the standpoint of social equity, particularly in Latin America owing to its poor income distribution, the extent of unmet basic needs, and because access to higher education is only gained after a screening process at the lower levels of the education system that eliminates the poorest first. It could also be advantageous for public institutions of higher education to diversify their financial resources to make them less dependent on public funding, with the inherent risks of instability and stagnation whose impact has been felt in their recent past. The problem in striking a better balance between public and private financing in the large public universities in th

Furthermore, higher education in Latin America has already $b$

seems to have led to a reduction in the average quality of the studies offered owing to the prol

solution to this problem, which is a social one since it affects the competence of the human resource base, could also lie in a better balance between private and public financing, although naturally the shares of each cannot be the same in institutions operated by those two sectors.

Turning to financing for innovative activities in businesses, the nature

ince impact o determine whether there are mechanisms to provide 
funding for those that are willing and able to innovate, outside of large corporations and individuals with capital to spare. A significant share of technology developm

and start-ups launched by experts in science and technology who frequently come from universities and who band together to capitalize on an idea with commercial potential. The main $\mathrm{p}$ by such companies is that they generally have very little seedcapital, and therefore it is vital for them to have access to at least one source of financing.

In the developed countries, financing can take the form of incentives for innovation such as direct government subsidies for $R \& D$ and tax reductions, or it can be risk capi

banks and other financial inst sources is used depends on the nature of the project, the $\mathrm{d}$ interest, and the creation of ex of government assistance, such as tax incentives, subsidies on profits or production, can be useful for ongoing innovation in well esta not so much for startup compa perform their $R \& D$ and reach the production stage before they can benefit from incentives of that kind.

\section{In Latin America and the}

few sources of funding for $R \& D$ and other technological innovation activities. Where technology development funds exist, they are generally small and unseasoned. There are very few firms specializing in risk capital investments in technology development, with exceptions in a few countries. The terms of loans and the guarantees required by the financial system normally make it difficult for small competent companies to finance R\&D.

usually interested in or capable of evaluating the commercial (to say nothing of the social) potential of a new idea for technology or of the technical capability of the proponents to capitalize on it. Consequently, that potential amounts to nothing when it comes to granting loans. For these reasons, the

\section{amount of \\ lower than it could and should be from the social standpoint.}

The principles for overcoming the restrictive financial scenario in the region are: when the externalities, lead times, and technological risks of an $\mathrm{R} \& \mathrm{D}$ project are large, government subsidies to supplement a business's own funding are the best means of support. It should be underlined that these are not indiscriminate subsidies, but very selective ones to overcome the obstacles discussed above. A project with low risk and a reasonable lead time, whose products can be fully appropriated by a company does not need a subsidy, it needs credit. If the financial market is too imperfect to supply it, the government should correct the situation, even by establishing specific funds to finance projects of this kind. Intermediate situations exist between these two extremes which, in principle, could be best addressed through risk capital investments. If this type of investor is absent, other alternatives to provide funding will have to be turned to temporarily, such as special forms of shared risk credit and the establishment of semipublic risk capital companies to promote investments of this kind in the country. Development of the above implies a learning process in society, which includes attempts, failures, and successes.

The principles suggested above can be put into pract operating procedures. A closer analysis should be performed of past experiences financed by the Bank and others in the region (e.g. Fundación Chile) and outside the region (e.g. the semipublic risk capital ventures in Korea, subsidies in Israel, etc.) to see which function better in different contexts and for different purposes. For example, completely different forms of financing may be required for: (a) minor modifications in production processes, and (b) more complex product innovations. The effectiveness of measures may also depend on the size, type, maturity, and other features of the business. The main point is 
that financing for technological innovation for companies in the region should be expanded considerably, while encouraging the companies themselves to invest much more in R\&D. Some specific mech

that produce $S \& T$ and the companies that use it are discussed below.

B.

\section{Financing mechanisms for the supply of S\&T}

Budget allocations to $\boldsymbol{S \& T}$ institutions. This is the more traditional mechanism which consists of granting an annual budget or nonreimbursable transfer from the government to entities that engage directly in S\&T, such as universities and research institutes. The mechanism serves to guarantee the survival of those institutions, permit the continuity of their work and keep the time they spend on financial administration to a minimum. It also provides a climate of independence in academic work, provided the budget allocations are stable. However, this instrument does not in itself contain any incentive for productivity or for tailoring products to the needs of potential users. Mechanisms for the periodic evaluation of results can be added, but it is not usually very easy to link the findings of such evaluations to changes in subsequent budgets.

Competitions for $R \& D$ and services projects. In this case, funds are allocated through open competitions based on peer review. Proposals compete with each other, based on previously published prerequisites. Decisions are made by committees of experts in the respective fields of knowledge, who are called upon to make impartial judgements regarding the quality and relative merit of projects submitted to them for consideration. As mentioned earlier, this mechanism has proven to be effective in many countries in establishing and maintaining strict R\&D quality standards. The procedure creates strong incentives for scientific effort and exactitude. However, it also creates a high degree of uncertainty unless it is combined with more stable mechanisms, and can lead to discontinuity and disruptions that are detrimental to long-term productivity. A further problem is the tendency to benefit more advanced groups and to focus financing too narrowly on them, since the more experienced researahers perform better in competitions, which makes it difficult to support emerging groups or the development of new centers with future potential. Last, this mechanism works better for financing science than technology, since it is primarily geared to supply; its use in the development of technologies and services may lead to waste in the form of underused facilities, prototypes and processes.

Competitions based on demand. In the case of R\&D and services that seek results that can be directly used in socioeconomic activities or trans

eligibility can be made conditional upon the applicant demonstrating that there is interest in using the resul

cost/benefit analysis under uncertainty conditions. The mechanism

above, but in this case is linked to demand by potential users in the production or social sectors. The project evaluators judge the scientific and technical merit of the proposal, but they also look at its socioeconomic relevance and the probability of its having an actual impact on society. However, it is often difficult to evaluate that probability and the seriousness of the commitment of potential clients. Strict demands on those clients, such as contributing cofinancing, tend to exclude high-risk technology projects and those which have social benefits that cannot be appropriated by the persons contributing funds (externalities). Very lenient demands, such as letter

Nevertheless, if the idea is to obtain new products, processes or designs, this mechanism is preferable to the other. The contrary holds true if the idea is to make progress in knowledge with longer lead times before it can be applied.

Grant and loan mechanisms for training researchers. The direct costs of training researchers 
are usually very high, as are the opportunity costs or the sacrifice of income that could be earned from other activities during the post-graduate training period. Since future salary expectations from S\&T activities are not generally very high, virtually all countries use grants or other subsidy mechanisms for post-graduate training. In some cases, however, loans or combinations of grants and loans can be used, and in fact have proven considerably more efficient than traditional scholarship programs in the region. Under this mechanism, a loan is granted to a candidate, who must necessarily be sponsored by an S\&T institution. The institution guarantees future employment and the candidate agrees to work full-time for that institution for a given perio Depending on whether these commitments are honored, the loan can be forgiven gradually until the end of the period agreed upon. A loan is usually guaranteed by the sponsoring institution and/or by individuals with stable jobs in the country.

Financing for S\&T infrastructure. In the case of the construction of infrastructure (laboratories, libraries, computer centers, etc.) for R\&D and for post-graduate training and science and technology services, financing is required for the physical facilities to enable $S \& T$ activities to be carried out rather than for the activities themselves. The scientific merit

of producing a given product or process are not evaluated in this case.

for such facilities for given stable lines of S\&T, the priority of those lines, and how much use will be made of the infrastructure over different time horizons. In general, the mechanisms described earlier for S\&T activities are also applicable to financing for infrastructure. In some cases that financing can be provided on a competitive basis for public and nonprofit agencies, but there are also occasions when direct allocations of capital are expedient, fo in developing or upgrading certain institutions or for other reasons, such as the lack of practical alternatives.

\section{International co}

mechanisms can include cooperation among countries in S\&T. For example, many $R \& D$ projects are carried out in conjunction with researchers from other countries or with their advice, and most Latin Americans and Caribbeans who complete postg outside the regio international cooperation in this field such as the Bolívar P operate $\mathrm{W}$ and through charges for the services they provide.

C.

\section{Forms of financing on the demand side}

Funds provided by the users of technology. Businesses invest their own funds in R\&D and science and technology services. For many reasons having to do with market failures, economic size, excessive risk, lack of experience, and so on, they do so in much smaller amounts than would be desirable from the standpoint of collective interest. However, self-financing continues to be a significant source of funding for technological development, which often moves forward through a series of small improvements or successive incremental innovations that frequently stem from uninstitutionalized and informal R\&D. The most important corollary is that public policies should promote supplementary mechanisms to finance R\&D as well as a climate of competition that will stimulate creativity and innovation.

Risk capital. In the industrialized countries, investors have appeared who specialize in financing the development of new products and processes. They make high-risk investments, frequently in small startup companies, which have extremely high returns when the R\&D achieves what it sets out to do. Except in some isolated cases, like the Companhia Riograndense de Participações in Brazil, there are still no investors of this type in Latin America and the Caribbean. 
Direct financing for users of technology. This mechanism transfers resources from the government through a specialized institution or a technology development fund to businesses interested in using a new technology which they intend to develop or adapt in their own laboratories or to contract out to a science and technology service for development. This maximizes the probability of socioeconomic use of the results of R\&D and focuses efforts on those who have the best practical knowledge of production processes and their requirements. This mechanism is therefore generally the most effective for developing or modifying new products or processes. Its main limitations in the region stem from the scant $R \& D$ tradition and capacity of the region's production sectors and their aversion to the inherent risks. Resources can be transferred on a nonreimbursable basis through competitions, or in the form of subsidized or unsubsidized loans. One significant risk is that scarce public funds will be used on unjustified subsidies that only favor private interests. However, learning about innovation in an economy that is unaccustomed to $R \& D$ is, in itself, strongly in the public interest. In general, subsidies for part of the cost of a project are justified when there are externalities, large

Tax exemptions. This mechani deductions for company investments in R\&D. The logic is the same as for direct government subsidies for R\&D, but it has at least two different charact $\mathrm{e}$ well-established modern businesses that are already turning a profit. It does not work well for startup companies established to capitalize on an idea with commercial potenti of $R \& D$ and reach the production stage before they can benefit from incentives of this type. Compared to the case-by-case evaluation of direct subsidies, this mechanism is less able to distinguish the degree of public interest in R\&D that would justify the use of public resources. It is thus a more automatic, less selective, and perhaps less effective mechanism in the context of the region.
D.

\section{Suggested objectives for the operations of the Bank}

T n

operations are presented below. However, in each oper

circumstances of the respective country and be W

objectives.

Escalate and refocus national $R \& D$ efforts. The percentage of each country's GNP that goes to R\&D should be increased until it reaches internationally acceptable levels for its development status. At the same time, government efforts should be refocused to do what the market cannot do and to create conditions that will facilitate an even faster increase in private R\&D expenditure. An adequate balance needs to be struck and maint

to conduct high-quality research in a variety of disciplines and the "specialized capacities" that are selectively required in some fields of special interest for the socioeconomic development of each country. The required equilibrium can vary a great deal from one country to another and from one period to another in the same country. Some important areas for R\&D in every country are those related to meeting the basic needs of the poor (education, health, nutrition, housing, etc.), rational management of natural resources, and environmental protection.

$\mathrm{r}$

Ensure a closer matching of S\&T supply and demand. Previous S\&T strategies have favored the supply side. The results have been neither bad nor insignificant; human resources had to be trained, and institutions had to be created and developed. There has also been inefficiency, however, in the form of output that finds no consumers, and technologies that are produced because there are scientists and budgets, not because someone is prepared to use them. Therefore, in those countries of the region that have already created a significant degree of S\&T capability, it is important to directly stimulate demand 
for (utilization of) knowledge rather than supply (production) in order to make the best use of installed capacity and selectively guide its growth. In practical terms, this means granting funds to the users of technology and to its producers who succeed in entering into contracts with prospective users. On the other hand, in many countries the capacity to supply needs to be expanded considerably, so that it can significantly respond to demand.

Promote the dissemination of existing technologies which are appropiate for the conditions of each country. It is important to disseminate technologies that increase the competitiveness of firms in the region, particularly small ones. This objective involves strengthening a set of information and technology transfer mechanisms, including sci-tech services (laboratory analysis, consulting, standards, metrology, quality control, etc.), connection with international information networks, efforts to adapt foreign technologies, technical training of personnel and the necessary infrastructure for achieving all of these ends.

Encourage firms to engage in $R \& D$. The expansion of capabilities in the productive sectors as countries and businesses strive to remain economically competitive will boost corporate demand for knowledge and new techniques. One major difficulty in increasing their in-house $R \& D$, which the Bank can help overcome, lies in the fact that financial instruments currently offered by commercial banks in the region are inadequate for this purpose, due to frequent repayment-term and guarantee problems and because they ignore market failures $(R \& D$ externalities, indivisibilities, excessive risks, etc.) and the need to build markets for technical and financial services for technological innovation.

\section{Remedy shortages of qualified human resources.}

Although good-quality education at all levels is a prerequisite for sound S\&T development, overall improvement in the quality of activities and institutions in the sector is the province of education policy. There are, however, shortages of qualified human resources in the region, particularly in the natural sciences and engineering, which run the gamut from very severe and widespread in the smallest and poorest countries, to specific or limited to certain areas in the larger and more developed countries. $\mathrm{R}$

S\&T

therefore, the Bank should provide for actions and investments that are appropriate to the situation in each country and that help meet that prerequisite. This could include, for example, loan-scholarship programs for advanced training abroad for scientists and engineers, with reasonable precautions to ensure their return to their home country, and the strengthening of some domestic post-graduate programs.

\section{Coordinate public policy and create incentives for} system-wide collaboration among NIS stakeholders. The interaction among companies, universities, financial institutions and government agencies must be strengthened. Coordinating public policy involves not only $\mathrm{R} \& \mathrm{D}$ financing, but also preventing inconsistencies and taking advantage of complementarities between different government actions, and ensuring that incentives in and outside the market are appropriate. For example, it is important to consider whether local producers are operating at a great disadvantage compared to those in other countries or whether, on the contrary, there are market reservations that nullify competition and the incentives to efficiency. Some policy instruments that can $\mathrm{h}$

ment are legislation and administrative practices relating to in

ment,

Educational and cultural policies (popularization of science) are, of course, directly related to the prospects for the advancement of S\&T. The Bank can contribute to these objectives through dialogues among stakeholders, because to the extent that they share a vision of the future, the attainment of all the other objectives is facilitated. Through analysis and policy conditionalities in the programs it finances, the Bank can also suppor

key interactions of NIS participants in order to 
strengthen the group's synergy.

Support international cooperation in $S \& T$. Collaboration in this field among the countries of the region has been scarce. IDB can contribute to increase and improve it by financing regional technical-

\section{E.}

\section{Typical components in a Bank-financed S\&T program}

This section suggests typical components that could be included in a project or program financed with an IDB loan. Assuming that the project complies with the general requirements of Bank policies for all operations, the S\&T investments and actions it calls for can be divided into seven main types of components, which may be combined in different ways: (i) technology development funds; (ii) funds for financing research and S\&T services through competitions; (iii) human resource training; (iv) infrastructure strengthening; (v) technology diffusion; (vi) information and popularization; and (vii) study and coordination of NIS policies.

Since programs financed with Bank loans frequently include a large number of relatively small subloans that transfer the proceeds to the end-users, lines of credit are often established, administered by a financial institution or executing agency in accordance with mutually agreed-upon criteria and procedures. To avoid confusion, the term "projects" is used below to designate subloans and the term "program" to designate the entire set of components for which a Bank loan is granted. Several aspects applicable to subloans are described below.

\section{(i) Technology development funds}

A technology development fund is a line of credit established in a country to provide financial and technical support for projects to develop or introduce cooperation projects and, also, through components of national programs that include different types of interchanges between the borrowing country and other member countries of the Bank.

technological innovations, i.e. improvements in products or processes that are new for the units that produce the respective goods and services. Eligible activities include $\mathrm{R} \& \mathrm{D}$, personnel training, and scientific and technical services. Only the investment and incremental operating costs during the execution period that are necessary to attain the objectives are eligible for financing. The eligible entities are the businesses operating in the country. Three possible types of subloans for technology development projects are discussed below.

Reimbursable loans. In this case, the goods procured and the results achieved as a result of the financing belong to the loan beneficiary, but the latter must repay the entire loan and the finance charges at positive real interest rates. This approach is particularly s 1

provide science and technology services that are paid for by users.

Shared risk and benefit financing. This approach differs from the above in that the results and benefits of the project

ciary company and the financial institution according to preset percentages. However, if the project is not successful, the executing agency may forgive a predetermined part of the loan received by the beneficiary. The idea is to adapt to the financial requirements of applied research projects which entail high risks but which also have the possibility of producing results that can largely be appropriated. Basically, this approach attempts to do the same thing as risk c 
natively, support could be provided for the establishment and strengthening of risk capital funds in those areas in which there are no legal restrictions on Bank activities.

Subsidies. In this type of operation, the beneficiary is not required to repay the financing, but the results of the project are jointly owned by the beneficiary and the executing agency. This approach is suitable for basic research projects and for applied research with no immediate prospects of transfer to production activities, or when there are strong externalities and it is therefore difficult for the entity conducting the project to appropriate the economic benefits. It is also suitable for financing science and technology services which, owing to their nature, are provided free of charge.

\section{(ii) Competitions for nonreimbursable financing for research and $S \& T$ services projects}

Periodic competitions are established (for example, annually) which are

parties in sites published in advance. The members of the research community working in a government institutes and agencies, and private nonprofit organizations are eligible to compete. All the applications received are evaluated by international specialists in the criteria of excellence (scientific or technical evaluation) and by experts (mainly economists) of the country on the basis of their importance for development (economic evaluation). The final decision is made by panels established by the executing agency.

Three types of projects are distinguished for the purposes of economic analysis: (a) research projects whose results can be transferred immediately to the production apparatus; (b) research projects whose results cannot be transferred immediately; and (c) scientific and technical services projects.
A $r$

transferable when the lead time between production of the results (upon completion of the research) and their introduction into the production process is equal to or less than a given period (four years for example). The introduction is considered to take place when investments are made in the plant and equipment required to produc in the case of an innovation that does not require such investments, when it comes into production.

Pro

through a cost/benefit analysis under uncertainty conditions, using different ranges of probability for the uncertain values. Research projects whose results cannot be immediately transferred may be reviewed to determine whether they are germane to other possible research for immediate transfer. Scientific and technical services projects should be analyzed on the basis of demand for those services and, when the benefits of the projects can be quantified, a cost/benefit analysis should also be performed.

For a project to be eligible, it should meet the following general criteria: (a) the project analysis should show that the proposed research or services are relevant for the country's development; (b) the project should have competent personnel and, in the case of research, there should be a reasonable possibility that results can be obtained, in light of the rigor of the methodology and the resources that would be allocated to the project, if approved; (c) for research projects for immediate transfer, it should be demonstrated that at least one enterprise or user is interested in adopting the results if the research is successful; and (d) research projects that cannot be immediately transferred should have strong linkage with other fields of research that are likely to produce immediate applications and should be intended to strengthen their foundations. Eligible projects are ranked by two variables: quality and potential socioeconomic impact. The weighting of these variables depends on the panel and may vary by subject area and country. 
To ensure that a program is consistent with a country's socioeconomic development priorities, while avoiding rigid conditions that would hamper execution, it is important that the control variables required contractually and the eligibility criteria be properly selected. For example, limits should be placed on the maximum funding that a program can earmark for research projects that are not immediately transferrable and caps should be established on financing for any given research or services project.

Samples of projects help illustrate how the criteria and procedures agreed upon will be applied; they are also useful to infer the characteristics of the universe of projects to be financed and to ensure that an adequate number of projects are ready to be carried out. The Bank should require the presentation of several prospective projects for competitive funding and for the technology development funds discussed earlier. The samples should be analyzed in detail prior to approval of the loan.

\section{(iii) Human resource training}

Programs may include resources for training the staff of public and private research and service centers, including those of businesses. These funds are usually administered by a central science and technology institution in the country. Training can take the form of regular academic programs (masters' degrees, doctorates and post-doctoral studies) or different types of in-service training and short courses (up to one year) in any Bank member country.

The executing agency distributes the funding in accordance with a plan agreed upon with the Bank, which generally uses the grant-loan approach. Under this approach: (a) the financing is not a donation but a special loan; (b) if the entity sponsoring a candidate is a for-profit company, the loan cannot be forgiven; (c) if the entity is a government institution or a private non-profit organization, the loan may be forgiven under certain conditions; (d) these conditions include the requirement that the recipient agree to work fulltime for a preset period for the research or service center that applied for the grant-loan.

For an application for a grant-loan to be approved as part of $t$

program, the following eligibility requirements typically a

for by a research or service center; (b) the applicant centers must carry out scientific or technological activities in areas that are relevant to the country's development and must also demonstrate that they need $\mathrm{t}$

within a

following the date of the application) and agree to employ the grant-holder for at least twice as long as the duration of the proposed studies; (c) grant-loans are given only in engineering, technology, or natural, exact, agricultural or medical sciences; (d) grantloans may not be given for studies abroad if such studies are offered locally at the required level; and (e) the candidates must have the appropriate academic background and be qualified and competent to carry out the proposed program, and must agree to work for the applicant center for at least twice as long as the duration of their studies.

With a view to adequately scaling determining its contents, the Bank should request that a surv

resource requirements of the main research and service centers in the country.

\section{(iv) Infrastructure strengthening}

Science and technology programs can include component

$\mathrm{f}$

con

laboratories a

are $n$

including services such as standardization, metrology, quality control, meteorology, microscopy, computing, 
documentation, and for post-graduate teaching.

Given the size and specificity of the investments required for infrastructure, the Bank should normally require that all the investments included in this component be identified and justified as a series of specific projects. However, when the objective is not to create new major infrastructures but to strengthen and expand certain specific aspects of existing units, the Bank could proceed as for competitive projects.

The following criteria should be fulfilled to include a given project in this component: (a) the investments must be indispensable for conducting a structured research program, post-graduate teaching, or S\&T services in areas that have been defined as eligible for loan proceeds; (b) there should be effective demand for the services offered by the project, equal to or greater (within a reasonable time period) than the total capacity generated by it; and (b) the increase in recurring costs caused by the project should be covered, if possible, by an increase in income from the sale of services or other forms of cost recovery, except in the case of free public services or research whose results canno

$\mathrm{t}$ activities.

\section{(v) Technology diffusion}

Bank operations can include components for establishing or strengthening $\mathrm{m}$ advisory services and the disseminat particularly for small and medium-sized businesses. The 1

ad hoc units or centers $i$

associations, technology institutes, universities, and other institutions that develop knowledge and techniques. These units could provide information and technical assistance, linkage between R\&D institutions services.

\section{(vi) Information and popularization}

The programs financed by the Bank could include science and technology information and popularization. This involves the strengthening of information centers, the establishment of networks, and their connection to the Internet. It also includes the publication of books, journals, CD-Roms and messages in different media, and other activities specifically designed to at the disposal of users. It could also include fairs, exhibitions, science awards, student competitions, international events, and other mechanisms that contribute $\mathrm{t}$

technology as components of the national culture.

\section{(vii) Study and coordination of NIS poli- c}

The programs can also include studies of the entire gamut of issues discussed in this document, mechanisms for dialogue and consensus building among stakeholders, and efforts to coordinalbe the public policies that have the greatest impact on the NIS, including intellectual property, technical standards, government procurement, university-business linkage, and the salaries of researchers.

The preceding description of components has been very general and the reader is referred back to the chapters on the different types of countries and the analysis of S\&T interfaces for more discussion on the purposes of such components. Each country has its special characteristics and each historical situation is unique and immensely rich. We have not wished to reduce this wealth to molds or behaviors based on simple formulas, but to suggest avenues that only the countries can travel, always reinventing them. 


\section{-VI- \\ EPILOGUE}

According to a popular saying that we often hear but rarely or never see written down, small and poor countries should not invest in science because "you shouldn't buy caviar when you can't even afford bread." Some people think that science is a luxury that is not appropriate for countries that have large unmet basic need

countries should not concern themselves very much with technology, because the market will spontaneously provide all that is needed.

It can be demonstrated theoretically and historically that this last statement is incorrect and is not backed up by evidence. $\mathrm{M}$

market from doing what it can, but to assist it in doing much more. As for bread, science can help a great deal to make more of it available, and poor countries need the most basic staples precisely because they are still unable to tap the benefits of scientific knowledge. Considering the future of those countries over a long horizon, to deny the need of at least a modest scientific infrastructure of their own is to suggest to them, deliberately or not, that they should always live submissively and poorly. This document takes the opposite approach to those unwritten recipes, which unfortunately, have a considerable impact on government policies.

As for the Bank, when its cooperation is requested, the best assistance it can give to small and poor countries is to contribute to the gradual and realistic construction of solid foundations for their own scientific and technological capacity; for the larger and not-so-poor countries which it has already helped somewhat to do just that, it should now assist them in continuing to consolida better use of them. 


\section{REFERENCES}

Abeledo, C., (1990). Linking R\&D to Industry: The Latin American Experience. Typescript.

Abeledo, C., (1985). Vinculaciones entre Laboratorios Patrocinados por el CONICET y el Sector Productivo en Argentina. Trabajo presentado en Seminario Internacional sobre Vinculaciones Institucionales para el Desarrollo Tecnológico, São Paulo, noviembre de 1985.

Abramovitz, M. (1956). "Resource and Output Trends in the U.S. since 1870". American Economic Review. Papers and Proceedings, 46.

Arocena, R. y Bortagaray, I.

Arregui,

la América Latina". En Progreso Económico y Social en América Latina.

Arrow, K. (1962). "Economic Welfare and

Rate and Direction of Inventive Activity, Princeton, N.J.: Princeton University Press.

Bailey, T., y Eicher, T. (1994). "Educ

XXXVIII, No. 119.

Banco Interamericano de Desarrollo (1995). Política No. OP-743 (Educación), No. OP-744 (Ciencia y Tecnología) y No. OP-721, numeral 2 (Sector Agropecuario, Investigación y Extensión). Manual de Políticas Operativas. Versión revisada de marzo de 1995.

Banco Interamericano de Desarrollo (1994

Documento A-1704.

Banco Interamericano de Desarrollo (1988), Apéndice Estadístico sobre Ciencia y Tecnología. En Progreso Económico y Social en América Latina. Informe 1988. Washington, D.C.: BID.

Banco Interamericano de Desarrollo (varios años). Informes de Proyecto citados por su respectivo número de identificación: 109/IC-CO, 110/IC-CO, 435/OC-BR, 715/SF-BR, 515/OC-AR, 544/OC-CR, 588/OC-CO, 604/OC-VE, 620/OC-BR, 646/OC-UR, 647/OC-UR, 672/OC-CH, 679/OC-RG, 680/OC-RG, 681/OC-RG, 802/OC-AR, 804/OC-ME; 874/OC-EC, 875/OC-CO y 880/OC-BR.

BID/SECAB/CINDA, (1990) Vinculación Universidad/Sector Productivo. Santiago de Chile: CINDA (Centro Interuniversitario de Desarrollo).

BID (1995). Misión al Uruguay sobre Ciencia y Tecnología; Ayuda de Memoria de 10 de octubre de 1995.

Bifani, P., (1988). "Biotecnología: Perspectiva General y Desarrollos en América Latina". En Progreso Económico y Social en América Latina. Informe 1988. Washington, D.C.: BID.

Branscomb, L. (1995). "United States Science and Technology Policy: Issues for the Nineties". In Science and Technology in Brazil: A New Policy for a Global World. Rio de Janeiro: Fundaçao Getulio Vargas. 
Brooks, H. (1986), "National Science Policy and Technological Innovation". In Landau, R., and Rosenberg, N. (Ed.). The Positive Sum Strategy. Harnessing Technology for Economic Growth. Washington, D.C.: National Academy Press.

Brunner, J.J., (1990). "Educación Superior, Investigación Científica y Transformaciones Culturales en América Latina". En BID/SECAB/CINDA, Vinculación Universidad/Sector Productivo. Santiago de Chile: CINDA (Centro Interuniversitario de Desarrollo).

Cáceres, L.R. (1994) "Costos y Beneficios de la Integración Centroamericana". Revista de la CEPAL. No. 54.

Castro, C. M. (1986). É Possível uma Tecnología "Made in Brazil"?. São Paulo: PROMOCET (Companhia de Promoção de Pesquisa Científica e Tecnológica Do Estado de São Paulo).

Castro, C. M.; Levy, D.C; and Bernasconi, A.; (1996) Higher Education in Latin America and the Caribbean: Myths, Realities and How the IDB Can Help. Typescript.

Cent $\mathrm{r}$

o

Financiamiento y Gestión de

Centro Nacional de Consultoría de Colombia (1994). Evaluación del Programa BID. Primera Etapa. Mimeo.

CEPAL - UNESCO (1992). Educación y Conocimiento: Eje de la Transformación Productiva con Equidad. Santiago de Chile: Naciones Unidas.

COLCIENCIAS (1994). Diez Casos Exitosos de Innovación Tecnológica Bogotá: COLCIENCIAS.

CONICIT - Costa Rica (1995). Resultados de Proyectos de I\&D. Mimeo.

CONICYT - Uruguay (1995). Ciencia y Tecnología para el Desarrollo del Uruguay. Montevideo: Consejo Nacional de Investigaciones Científicas y Técnicas.

Cook, C. y Sagasti, F. (1987). "La Ciencia y la Tecnología durante el Decenio de los Ochenta". Comercio Exterior, Vol. 37, No. 12.

CORFO (1995). 100 Proyectos Innovadores, Santiago: Corporación de Fomento de la Producción.

Corona Treviño, L., (1994). "Educación, Ciencia y Tecnología: Un Escenario Alternativo". Comercio Exterior, Vol. 44, No. 3.

Cruz, A., y Dory

ámbitos Productivo, Académico y Gubernamental de Honduras. Tegucigalpa: CONICIT/ PNUD.

Cuervo, A. y Melo, D. (1994). Seguimiento y Evaluación Ex-post del Crédito BID-II de Colombia. Mimeo.

CYTED/RICYT/OEA/MERCOCYT (1996). Indicadores de Ciencia y Tecnología 1990 - 1995. Quilmes: Universidad Nacional de Quilmes.

Chamarik, S. and Goonatilake, S. (1994) Technological Independence. The Asian Experience. Tokio: The United Nations University. 
Chesnais, F. (1993) "The French National System of Innovation". In Nelson R.R. (Ed.), National Innovation Systems. A Comparative Analysis. New York, Oxford: Oxford University Press.

Dahlman, C. (1995). Technology, Development and the Role of the World Bank. HRO Working Papers. HROWP53. Washington, D.C.: The World Bank.

David, P. (1986). "Technology Diffusion, Public Policy, and Industrial Competitiveness". In Landau, R. and Rosenberg, N. (Ed.). The Positive Sum Strategy. Harnessing Technology for Economic Growth. Washington, D.C.: National Academy Press.

Declaración de Cartagena y Plan de Acción. Reunión Hemisférica de Ministros Responsables de Ciencia y Tecnología. Marzo de 1996.

Diebold, J. (1991). The Innovators. The Discoveries, Inventions and Breakthroughs of our Time. New York: Truman Talley Books/Plume.

Doryan, E. (1990). Primera Versión de la Propuesta de Política y Prog

Mimeo.

Doryan, E. y Alonso, E. (1991). Informe de Cumplimiento del Numeral 18 de la Declaración Presidencial de Puntarenas acerca del Proyecto de Modernización de Tecnología de los Sectores Productivos. Mimeo.

Eisemon, T.O. and Holm-Nielsen, L. (1995). Developing Capacity for Research and Advanced Scientific Training: Lessons from World Bank Experience. ESP Discussions Paper Series. Washington, D.C.: The World Bank.

Forsyth, D.J.C. (1990). Technology Policy for Small Developing Countries. The MacMillan Series of ILO Studies. London: The MacMillan Press.

Freeman, C. and Lundvall, B.A. (Eds.) (1988). Small Countries Facing the Technological Revolution. London: F. Pinter Publishers.

Frischtak, C. (1992). Learning, Technical Progress and Competitiveness in the Commuter Aircraft Industry: An Analysis of Embraer. Industry Series Paper No. 58. Washington, D.C.: The World Bank.

Frischtak, C. (1996). O Impacto do Regime de Propiedade Intelectual sobre O Desempenho Tecnológico da Industria Brasileira. Mimeo.

Fundación Centro de Biosíntesis de Argentina/C.I.S. (1996). Exposición de Diez Casos Exitosos de I\&D Realizados en Argentina por Centros e Institutos del CONICET. Mimeo

Fusfeld, H.I. (1994). Industry's Future. Chang

Chemical Society.

Gates, B. (1996). The Road Ahead. New York: Penguin Books.

Gibbs, W.W. (1995). "Lost Science in the Third World". Scientific American. (August, 1995).

Hafner, K. and Lyon, M. (1996). Where Wizards Stay Up Late: The Origins of Tne Internet. New York: Simon $\&$ Shuster. 
Hamm, I., (1996). "La tecnología de los "media" como Catalizador de la Reforma Educativa" en Educación y Desarrollo. Aprender para el Futuro". Madrid: Fundación Santillana.

Herrera, A. (1987). El Nuevo Paradigma Tecnológico y América Latina: Problemas y Opciones. Ponencia en II Seminario "Jorge Sábato" sobre Política Científica y Tecnológica; Madrid.

Hernández Alcerro, J.R. (1995). Memorando sobre Ciencia y Tecnología, Política OP-744, dirigido al Presidente del Comité de Políticas del Directorio Ejecutivo del BID, el 16 de junio de 1995.

Hou, Ch. M. and Gee S. (1993). "National Systems Supporting Technical Advance in Industry: the Case of Taiwan". In Nelson, R. R. (Ed.). National Innovation Systems. A Comparative Analysis. New York, Oxford: Oxford University Press.

Holm-Nielsen, L.; Saliba, A.; Crawford, M., (1995).

Science and Technology Sector: Setting a New Agenda. Workshop Synopsis. Washington, D.C.: The World Bank.

Iglesias, E.V., (1995). La Educación Superior y el Desarrollo Económico de América Latina: Necesidad de una Nueva Cooperación entre Universidades y Empresas. Mensaje del Presidente del BID en ocasión del $60^{\circ}$ Aniversario de la Universidad Autónoma de Guadalajara.

Iglesias, E.V., (1992). Reflexiones sobre el Desarrollo Económic

Washington, D.C.: Banco Interamericano de Desarrollo (BID).

Instituto de Relaciones Europeo-Latinoamericanas (IRELA) (1993). Ciencia y Tecnología en América Central. Manchester: IRELA.

International Institute for Management Development/The World Economic Forum (1994). The World Competitiveness Report - 1994. Lausanne: IMD.

\section{INVERTE}

de Chile. Mimeo.

Keck, O. (1993). " "The Nationa

Innovation Systems. A Comparative Analysis. New York, Oxford: Oxford University Press.

Kennedy, D., (1986), "Basic Research in the Universities: How Much Utility". In Landau R., and Rosenberg, N. (Ed.). The Positive Sum Stra Academy Press.

Kim, L. (1993). "National System of Industrial In

R. R. (Ed.) National Innovation Systems. A Comparative Analysis. New Y

Kline, S.J.and Rosenberg, N. (1986). "An Overview of Innovat Positive Sum Strategy. Harnessing Technology for Economic Growth. Washington, D.C.: National Academy Press. 
Lavados, I., (1987). "Actores Institucionales y Fuentes de Recursos para las Actividades de Investigación y Desarrollo". En Financiamiento y Gestión de la Actividad de Investigación y Desarrollo en Chile. Santiago de Chile: CINDA.

Lavados M., J., (

Promoción Universitaria (Ed), La Universidad Latinoamericana, Visión d

Licha, I. (1995). La investigación y las Universidades Latinoamericanas en el Umbral del Siglo XXI: Los desafios de la Globalización. Washington, D.C.: CISTP, The George Washington University.

Malek, G., (1979). "La Ciencia y la Universidad". En corporación de Promoción Universitaria (Ed), La Universidad Latinoamericana, Visión de Una Década. Santiago de Chile: CPU.

Magalhães Castro, M. H. (1996). Estudos de Cas

(1967-1995). Mimeo.

Mansfield, E. (1986). "Microeconomics of Technological Innovation". In Landau, R. and Rosenberg, N. (Ed.).

The Positive Sum Strategy. Harnessing Technology for Economic Growth. Washington, D.C.: National Academy Press.

Marcovitch, J. (1988). O Novo Contexto Mundial, Desafío Tecnológico e A Integracão Latinoamericana. XIII Simposio Nacional de Pesquisa de Administração em Ciencia e Tecnología: São Paulo.

Martín del Campo, E. (1989). "Technology and the World Economy: The case of the American Hemisphere". Technological Forecasting and Social Change, 35:4.

Martínez Pavez, C. (1996). C

Quilmes: Universidad Nacional de Quilmes.

Mayorga, R., (1978). "Eficiencia y Ju

Año XXXIII, No. 353.

Mayorga, R. (1989). Reduzcamos la brecha. Hacia una Estrategia Regional en Ciencia y Tecnología. Nota Técnica del Departamento de Análisis de Proyectos, (PRA), del Banco Interamericano de Desarrollo (BID).

Mowery, D.C. and Rosenberg, N. (1993). "The U.S. National Innovation System". In Nelson, R.R. (Ed.). National Innovation Systems. A Comparative Analysis. New York, Oxford: Oxford University Press.

Mullin, J., (1995) Breakin

and Technology. Ottawa: Canadian Foundation for the Americas.

National Science Foundation (NSF) (1995). Industry/University Cooperative Research Centers: A successful Experiment. Arlington, VA.: NSF.

Nelson, R.R. and Rosenberg N. (1993). "Technical Innovation and National Systems". In Nelson, R.R. (Ed.) National Innovation Systems. A Comparative Analysis. New York, Oxford: Oxford University Press.

Odagiri, O. and Gato, A. (1993), "The Japanese System of Innovation: Past, Present and Future". In Nelson, R.R. (Ed.). National Innovation Systems. A Comparative Analysis. New York, Oxford: Oxford University Press. 
Organization for Economic Cooperation and Development (OECD) (1995) Science, Technology and Policies. Denmark. Paris: OECD.

Oro, L.A. y Sebastián, J. (1993). Los Sistemas de Ciencia y Tecnología en

Pettit, J.M. (1986). "Technological Education". In Landau, R., and Rosenberg, N., (Ed.), The Positive Sum Strategy. Harnessing Technology for Economic Growth. Washington, D.C.: National Academy Press.

Plan de Acción. Cumbre de las Américas. Documento CS-2851-5.

PRA (1989). Aportes del BID al Desarrollo Científico y Tecnológico de América Latina y el Caribe. Nota Técnica del Departamento de Análisis de Proyectos (PRA) del Banco Interamericano de Desarrollo (BID).

Primo Braga, C.A. (1995). Trade Related Intelectual Property Issues: The Uruguayan Round Agreement and its Economic Implications. Paper presented at the World Bank Conference "The Uruguayan Round and the Developing Economies".

Programa Bolívar (1994). Notas para un Diálogo Urgente. Caracas: Enede, C.A.

Programa MERCOCYT (1995). La Competitividad Tecnológica de las Em

Una Revisión de la Situación Regional. Washington, D.C.: OEA.

Rada, J.F, (1996). "La Reforma de la Educación y el Desarrollo de Sistemas Paralelos" en Educación y Desarrollo. Aprender para el Futuro. Madrid: Fundación Santillana.

Rama, G. (1987) (coord.). Desarrollo y Educación en América Latina y el Caribe (Tomo 2). Buenos Aires: CEPAL/UNESCO/PNUD.

Roche Rivera, H. (1996). "Proyectos de Innovación Tecnológica a Nivel de Empresas Privadas en Uruguay". Mimeo.

Rosenberg, N. (1994). Exploring the Black Box

University Press.

Rosenberg, N. (1986). "The Impact of Technological Innovation: A Historical View". In Landau, R. and Rosenberg, N. (Ed.). The Positive Sum Strategy. Harnessing Technology for Economic Growth. Washington, D.C.: National Academy Press.

Rosenberg, N. and Birdzell, L.E. (1986). How the West Grew Rich. The Economic Transformation of the Industrial World. New York: Basic Books Inc., Publishers.

Sagasti, F. (1988). "Crisis y Desafío: Ciencia y Tecno

Vol. 38, No. 12.

Schwartzman, S., (1988). La Calidad de la Educación Superior en Améric

Eficiencia y Calidad de la Educación Superior en América Latina; Brasilia.

Secretaría General del Programa CYTED (1996). Naturaleza, Organización y Gestión del Programa Iberoamericano de Ciencia y Tecnología para el Desarrollo. Madrid: CYTED.

Sen, A.K. (1972). La Selección de Técnicas.

Fondo de Cultura Económica. 
Sercovich, F.C. y Teitel, S. (1984). "Exports of Technology by Newly Industrializing Countries. Latin World Development, Vol. 12. No. 5/6.

Sibaja, E. (199

Mimeo.

Solow, R. (1957). "Technical Change and the Aggregate Production Function". Review of Economics and Statistics, 39.

Spurgeon, D. (1995). Southern Lights. Celebrating the Scienti International Development Research Center.

Stähl, L.G., (1996). "Recursos e Innovaciones en la Aplicación de las Reformas Educativas" en Educación y Desarrollo. Aprender para el Futuro. Madrid: Fundación Santillana.

Sutz, J. (1993). Una Propuesta Progresista en Ciencia y Tecnología. Montevideo: FESUR.

Tal, E. (1985). "R\&D in Panama". Science and Public Policy-Volume 12, Number 5.

Teitel, S. (1985). "Indicadores Científ

en Vías de Desarrollo". El Trimestre Económico, Vol. LII (1), No. 25.

Teubal, M. (1995). R\&D and Technology Policy at NIC's as Learning Processes. Typescript.

Teubal, M. (1994). Towards an Evaluation of Chile's FONTEC and FONDEF Programs. Typescript.

Thulstrup, E.W. (1994). Scientific Research for Development. HRO Working Paper No. HROWP 25. Washington, D.C.: The World Bank.

Thulstrup, E.W. (1992). Improving the Quality of Reseach in Developing Country Universities. PHREE Background Paper Series Document No. PHREE/95/52. Washington, D.C.: The World Bank.

Trindade, S. (1996). Science and Technolo

Issues, Options and New Approaches for the Consideration of the IDB. Typescript.

Trindade, S. (1980). "Technology Development in Developing Countries: The Case of a Private R\&D Institution in Brazil". R\&D Management, Vol. 10, No. 2.

Urquidi, V. (1988). Requerimientos para una Política Nacional en Ciencia

Nacional sobre Investigación Científica y Desarrollo Tecnológico; Guadalajara.

Ventura, A. (1996). Science and Technology for Poverty Alleviation and Social Development in the American Hemisphere. Hemispheric Meeting of Ministers Responsible for S\&T. Typescript

Ventura, A. (1991). Influence of Small Size on Jamaica's Science and Technology System. Typescript.

Vessuri, H. y Díaz, E. (1985). Universidad y Desarrollo Científico-Técnico en América Latina y el Caribe. Caracas: CRESALC.

Vitro, R.A. (1996). Accelerati

Resources in Support of the 8th General Increase of IADB capital. Typescript. 
Vonortas, N.S. and Safioleas, S.P. (1996). Strategic Alliances in Information Technology and Developing Country Firms, I: Recent Evidence. Washington, D.C.: The George Washington University.

Walker, W. (1993). "National Innovation

A Comparative Analysis. New York, Oxford: Oxford University Press.

Waissbluth Subelman, M. (1996). Cooperación Científica y Tecnológica en América Latina y el Caribe: Su Evolución en la Década del 90. Quilmes: Universidad Nacional de Quilmes.

Waissbluth, M., Testart, E., y Buitelear, R. (1992). Cien Empresas Innovadoras en Iberoamérica. Valparaíso: Universidad de Valparaíso Editorial.

Waissbluth, M., et al (1988). "Linking University and Industry: An Organizational Experience in Mexico". Research Policy 17:6.

Weiss Jr., Ch. (1992). A Strategy for Technological Modernization in Latin America. A background paper prepared for the Strategic Planning Unit of the IDB. Typescript. 